\title{
Modeling dust as component minerals in the Community Atmosphere Model: development of framework and impact on radiative forcing
}

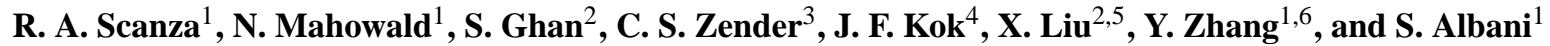 \\ ${ }^{1}$ Department of Earth and Atmospheric Sciences, Cornell University, Ithaca, New York, USA \\ ${ }^{2}$ Atmospheric Sciences and Global Change Division, Pacific Northwest National Laboratory, Richland, Washington, USA \\ ${ }^{3}$ Department of Earth System Science, University of California, Irvine, USA \\ ${ }^{4}$ Department of Atmospheric and Oceanic Sciences, University of California, Los Angeles, USA \\ ${ }^{5}$ Department of Atmospheric Science, University of Wyoming, Laramie, Wyoming, USA \\ ${ }^{6}$ Department of Environmental Science and Engineering, Fudan University, Shanghai, China
}

Correspondence to: R. A. Scanza (ras486@cornell.edu)

Received: 21 February 2014 - Published in Atmos. Chem. Phys. Discuss.: 2 July 2014

Revised: 18 November 2014 - Accepted: 3 December 2014 - Published: 15 January 2015

\begin{abstract}
The mineralogy of desert dust is important due to its effect on radiation, clouds and biogeochemical cycling of trace nutrients. This study presents the simulation of dust radiative forcing as a function of both mineral composition and size at the global scale, using mineral soil maps for estimating emissions. Externally mixed mineral aerosols in the bulk aerosol module in the Community Atmosphere Model version 4 (CAM4) and internally mixed mineral aerosols in the modal aerosol module in the Community Atmosphere Model version 5.1 (CAM5) embedded in the Community Earth System Model version 1.0.5 (CESM) are speciated into common mineral components in place of total dust. The simulations with mineralogy are compared to available observations of mineral atmospheric distribution and deposition along with observations of clear-sky radiative forcing efficiency. Based on these simulations, we estimate the all-sky direct radiative forcing at the top of the atmosphere as $+0.05 \mathrm{Wm}^{-2}$ for both CAM4 and CAM5 simulations with mineralogy. We compare this to the radiative forcing from simulations of dust in release versions of CAM4 and CAM5 $(+0.08$ and $+0.17 \mathrm{Wm}^{-2}$ ) and of dust with optimized optical properties, wet scavenging and particle size distribution in CAM4 and CAM5, -0.05 and $-0.17 \mathrm{Wm}^{-2}$, respectively. The ability to correctly include the mineralogy of dust in climate models is hindered by its spatial and temporal variability as well as insufficient global in situ observations, incomplete and un-
\end{abstract}

certain source mineralogies and the uncertainties associated with data retrieved from remote sensing methods.

\section{Introduction}

Dust aerosols are soil particles suspended in the atmosphere, and they impact the climate system by influencing the radiation budget, cloud processes (Miller and Tegen, 1998; Mahowald and Kiehl, 2003; Karydis et al., 2011; DeMott et al., 2003; Levin et al., 2005) and various biogeochemical cycles (Swap et al., 1992; Martin et al., 1991; Jickells et al., 2005). The radiation balance of the Earth system is affected by the scattering and absorption of solar and infrared radiation by mineral aerosols (Miller and Tegen, 1998; Sokolik and Toon, 1999). Magnitude and sign of radiative forcing of dust are considered to be two of the most uncertain aspects in determining the net radiative forcing from natural and anthropogenic aerosols (IPCC, 2007).

Previous and ongoing modeling efforts address the importance of determining the mineral composition of dust and its impact on the radiation budget (Sokolik and Toon, 1999; Claquin et al., 1999; Balkanski et al., 2007). A main factor in accurately determining the sign of dust radiative forcing is the inclusion of the mineralogical components that absorb solar radiation. For instance, iron oxides have 
large imaginary portions of their complex refractive indices (http://www.atm.ox.ac.uk/project/RI/hematite.html, cited as personal communication with A. H. M. J. Triaud, 2005). Since the imaginary part of refractive indices corresponds to absorption, iron oxide refractive indices control the amplitude of dust absorption in the solar and visible wavelengths (Sokolik and Toon, 1999; Claquin et al., 1999; Moosmüller et al., 2012). Efforts to separate the components of absorbing dust single out the iron oxides, e.g., hematite and goethite, although in this study we simulate the iron oxides collectively as hematite.

Recent modeling studies that consider the speciation of dust into its mineral components include work by Balkanski et al. (2007), Sokolik and Toon (1999), Nickovic et al. (2012) and Journet et al. (2014). Balkanski et al. (2007) report good agreement with satellite and AErosol RObotic NETwork (AERONET) data (Holben et al., 1998, 2001) when a $1.5 \%$ internally mixed volume weighted percent of hematite is modeled and report global mean top of atmosphere (TOA) and surface radiative forcings from -0.47 to $-0.24 \mathrm{Wm}^{-2}$ and -0.81 to $-1.13 \mathrm{Wm}^{-2}$ respectively. Sokolik and Toon (1999) investigate the optical properties of a mixture of individual minerals and of mixtures where hematite is aggregated with other minerals. They find a net negative radiative forcing for externally mixed minerals and a net positive forcing either when hematite concentrations are unrealistically high or when hematite is aggregated with quartz. Nickovic et al. (2012) present high-resolution mineral maps based on Claquin et al. (1999) mineral maps. The maps include some improvements, for example, hematite is represented in both the clay and silt soil fractions, along with mapping additional soil types and including maps with phosphorus. Journet et al. (2014) expand on the soil mineralogies from Claquin et al. (1999) by including many additional soil mineralogy measurements and increasing the number of minerals; however, these maps were not available at the time the simulations in this study were performed.

This study addresses the direct radiative forcing (DRF) of natural mineral aerosols in the Community Earth System Model (CESM). The global model simulations attempt to match the sign and magnitude of regional observations of DRF using two different atmosphere models. Dust in the Community Atmosphere Model 4, hereafter CAM4, was speciated into eight minerals - illite, kaolinite, montmorillonite, hematite, quartz, calcite, gypsum and feldspar (Claquin et al., 1999) - where the minerals along with other aerosols are treated as external mixtures (Mahowald et al., 2006). The Community Atmosphere Model 5, CAM5, treats aerosols as internal mixtures within two of three modes (Liu et al., 2012). Dust in CAM5 was speciated into four minerals, the major clays (illite, kaolinite and montmorillonite) and hematite, along with an additional tracer to carry the rest of the dust.

The main objective of this work was to build the framework to model dust as its individual mineral components and to test the accuracy of emission, advection and deposition of the mineral tracers by comparing with observations from the literature. An additional objective was to determine the radiative effect of speciating dust into minerals on the Earth system. Furthermore, the use of two different atmosphere models allows us to test the sensitivity of mineral speciation within different frameworks. The framework for carrying extra tracers performs reasonably well and is currently being used to investigate elemental distributions (Zhang et al., 2014) and also ice nucleation in mixed-phase clouds as a function of different mineral species.

The sections are organized as follows: Sect. 2 describes methods including a description of the CESM and CAM4 and CAM5 methods for dust entrainment, transport and deposition as well as the radiation schemes used to compute global estimates of DRF. Section 3 describes the resulting mineral distributions and compares them with observations, compares modeled optical depths and single scattering albedo to the AERONET ground-based sun photometers (Holben et al., 1998, 2001) and provides global and regional estimates of radiative forcing for both CAM4 and CAM5. Section 3 also presents two sensitivity studies, the first on the dust size distribution both to illustrate the significance of including mineralogy and to attempt to quantify the uncertainties associated with the radiative forcing from minerals. The second sensitivity study involves simulating mineralogy with hematite solely in the soil clay map to address recent studies that find hematite primarily in fine particle sizes and to investigate whether or not this improves our estimates of radiative forcing. The last section discusses the strengths of this framework and outlines where additional work is needed. Future improvements to these models will be described along with planned future simulations of trace nutrient biogeochemical cycling with this framework.

\section{Methods}

The Community Earth System Model version 1.0.5 (CESM 1.0.5), which is coordinated by the National Center for Atmospheric Research (NCAR) is a coupled Earth system model used to simulate past, present and future climate (Hurrell et al., 2013). This study uses CESM1.0.5 with modifications to CAM4 and CAM5.1 to simulate dust as distinct mineral tracers and to model radiation online to investigate the DRF of mineralogy.

\subsection{Desert dust model}

The CAM4 model configuration used for bulk aerosols contains active atmosphere, land and sea ice components, as well as a data ocean and slab glacier forced by NASA's GEOS5 meteorology (FSDBAM) (Suarez et al., 2008; Hurrell et al., 2013; Lamarque et al., 2012). Model resolution is on a $2.5^{\circ} \times 1.9^{\circ}$ horizontal grid with 56 vertical levels. The model 
was run for 8 years, 2004-2011, with the simulations from 2006 through 2011 used for analysis. The default configuration was altered so that radiative feedbacks onto climate were active and the radiation code was modified to compute radiation online, bypassing the need for Parallel Offline Radiative Transfer (PORT) (Conley et al., 2013). Because we use reanalysis winds, radiation does not feed back onto the meteorology. The dust model is part of a bulk aerosol model scheme with fixed bin width and sub-bin distribution following the Dust Entrainment and Deposition Model (DEAD) (Zender et al., 2003). The location and emission potential of dust source regions have been optimized from the default configuration and are described in Mahowald et al. (2006) and Albani et al. (2014).

Measurements and theory show that dust aerosols (0.1$50 \mu \mathrm{m})$ are primarily emitted through saltation, the bouncing motion of sand-sized $(\sim 100-200 \mu \mathrm{m})$ particles that disaggregate and emit dust aerosols via sandblasting from the saltating particles (Gillette et al., 1974; Shao et al., 1993; Kok et al., 2012). In order for saltation to be initiated, the wind stress on the surface needs to be sufficient to lift sand particles, which for bare soils, occurs above wind friction speeds of approximately $0.2 \mathrm{~ms}^{-1}$ (Bagnold, 1941; Kok et al., 2012). Dust entrainment in the Community Land Model (CLM), the land component of the CESM, is initiated after the wind speed exceeds the threshold wind speed calculated by the model. The threshold wind speed for dust entrainment increases with soil moisture: CLM uses the semi-empirical relation of Fecan et al. (1999) with additional optimization from the traditional dependence of the square of clay mass fraction (Fecan et al., 1999; Zender et al., 2003). Regions of dust emission are parameterized as being associated with topographical depressions where sediment from hydrological systems accumulates (Ginoux et al., 2001; Yoshioka et al., 2007; Mahowald et al., 2006; Zender et al., 2003). While measurements of dust particle size distribution range from about 0.1 to $50 \mu \mathrm{m}$, the CESM only accounts for the climatologically most relevant portion $(0.1-10 \mu \mathrm{m})$ (Schulz et al., 1998; Zender et al., 2003). Particle size distributions are computed from the mass fraction of an analytic trimodal lognormal probability density function representing three source modes to four discrete sink or transport bins by Eq. (1) (Zender et al., 2003):

$M_{i, j}=\frac{1}{2}\left[\operatorname{erf}\left(\frac{\ln \left(D_{\max , j} / \overline{D_{v, j}}\right.}{\sqrt{2} \ln \left(\sigma_{\mathrm{g}, i}\right)}\right)-\operatorname{erf}\left(\frac{\ln \left(D_{\min , j} / \overline{D_{v, j}}\right)}{\sqrt{2} \ln \left(\sigma_{\mathrm{g}, i}\right)}\right)\right]$,

where erf is the error function (Seinfeld and Pandis, 1998), and $D_{\max }$ and $D_{\min }$ correspond to the transport bins bounded at diameters $0.1,1.0,2.5,5.0$ and $10.0 \mu \mathrm{m}$ with a sub-bin lognormal distribution with mass median diameter, $\overline{D_{v}}$, of $3.5 \mu \mathrm{m}$ and geometric standard deviation, $\sigma_{\mathrm{g}}=2$ (Reid et al., 2003; Mahowald et al., 2006; Zender et al., 2003). The mass fraction in Eq. (1) is 0.87 for particle diameters $D=0.1-$ $10 \mu \mathrm{m}$, with the remaining fraction 0.13 centered around $19 \mu \mathrm{m}$. We assume this fraction is insignificant for long- range transport (Zender et al., 2003). Particle size distributions were parameterized (default mass fractions are 3.8 , $11.1,17.2$ and $67.8 \%$ for size bins $1-4$ ) following the brittle fragmentation theory of dust emission (Kok, 2011), with prescribed mass fractions in each bin of 1.1, 8.7, 27.7 and $62.5 \%$, respectively. The parameterized size distribution resulted in better agreement with AERONET size distribution measurements (Albani et al., 2014). Dry deposition includes gravitational settling and turbulent deposition, and wet deposition includes in-cloud nucleation scavenging and belowcloud scavenging (Rasch et al., 2000; Zender et al., 2003; Mahowald et al., 2006). The scavenging coefficients and particle solubility parameterizations were modified from $(0.1$, 0.1 for bins 3 and 4) to (0.3, 0.3 for bins 3 and 4$)$, and the prescribed solubility was changed from 0.15 to 0.3 (Albani et al., 2014). The suppression of dust emission by vegetation (Lancaster and Baas, 1998; Okin, 2008) was parameterized by assuming that the fraction of the grid cell consisting of bare soil capable of emitting dust aerosols decreases linearly with the leaf area index up to a threshold of $0.3 \mathrm{~m}^{2} \mathrm{~m}^{-2}$ (Mahowald et al., 2006).

The CAM5 model configuration used for modal aerosols is stand-alone atmosphere with land and sea ice components, as well as a data ocean and slab glacier, forced by NASA's GEOS-5 meteorology (Suarez et al., 2008; Lamarque et al., 2012; Hurrell et al., 2013) and CAM5 physics (FC5) (Liu et al., 2012). Model resolution is on a $2.5^{\circ} \times 1.9^{\circ}$ horizontal grid with 56 vertical levels. The model was run for 8 years using anthropogenic emissions from the year 2000, and years 2006-2011 are used for analysis. Radiative feedbacks were active and allowed to feed back onto climate but not meteorology. Dust entrainment processes are identical as described above for CAM4. The particle size distribution differs from the bulk aerosol method with lognormal functions describing the distribution via a modal aerosol model (MAM) (Liu et al., 2012). Mass mixing and number mixing ratios within a given mode are predicted, with fixed geometric standard deviation of each mode. Aerosol species including aerosol water are internally mixed within a mode and externally mixed between modes. Dust is carried in an accumulation mode (mode 1) and a coarse mode (mode 3 ) with diameter bounds at 0.1 $1.0 \mu \mathrm{m}$ and $1.0-10.0 \mu \mathrm{m}$, respectively. The particle size distribution for dust entrainment was modified (default mass percents are 3.2 and $96.8 \%$ for modes 1 and 3, respectively) following brittle fragmentation theory for vertical dust flux (Kok, 2011) with prescribed emission mass percents of 1.1 and $98.9 \%$ for modes 1 and 3. Advection and deposition processes are described in Liu et al. (2012), where aerosols are represented as both interstitial particles suspended in the atmosphere and as cloud-borne particles.

Source maps of minerals follow the mean mineralogical table (MMT) from Claquin et al. (1999), with two modifications. From the MMT, soil types whose mineral components are found not to add up to $100 \%$ were Gypsic Xerosols and Yermosols, Gleyic and Orthic Solonchaks and salt flats (Ta- 
Table 1. Mean Mineralogical Table from Claquin et al. (1999). Gypsic Xerosols and Yermosols (Xy,Yy), Gleyic Solonchaks (Zg), Orthic Solonchaks (Zo) and salt flats (ST) are renormalized to 100. Hematite is added to the clay fraction by subtracting the mass from illite following Balkanski et al. (2007) and Nickovic et al. (2011). For the sensitivity study involved in only a clay fraction source of hematite, the minerals with silt-sized source fractions were equally scaled from the mass removed from hematite.

\begin{tabular}{l|cccccc|ccccc}
\hline & \multicolumn{7}{|c}{ Clay fraction } & \multicolumn{5}{c}{ Silt fraction } \\
\hline Soil types & Ill & Kaol & Sme & Cal & Quar & Hem & Quar & Feld & Cal & Hem & Gyp \\
\hline I & 39 & 20 & 29 & 4 & 7 & 1 & 52 & 40 & 6 & 1 & 1 \\
Jc & 22 & 9 & 46 & 11 & 12 & 0 & 30 & 38 & 29 & 0 & 2 \\
Je & 17 & 23 & 55 & 1 & 3 & 1 & 86 & 10 & 2 & 1 & 1 \\
Qa & 20 & 54 & 21 & 0 & 4 & 1 & 83 & 15 & 0 & 1 & 1 \\
Qc & 12 & 67 & 5 & 1 & 11 & 4 & 80 & 14 & 1 & 4 & 1 \\
Qf & 22 & 48 & 23 & 1 & 5 & 1 & 82 & 15 & 1 & 1 & 1 \\
Q1 & 3 & 77 & 3 & 1 & 9 & 7 & 69 & 22 & 1 & 7 & 1 \\
Rc & 39 & 39 & 9 & 4 & 7 & 3 & 74 & 19 & 3 & 3 & 1 \\
Re & 30 & 52 & 10 & 1 & 5 & 2 & 58 & 38 & 1 & 2 & 1 \\
So & 35 & 32 & 17 & 6 & 7 & 2 & 70 & 23 & 4 & 2 & 1 \\
Vc & 12 & 27 & 48 & 4 & 5 & 4 & 31 & 61 & 3 & 4 & 1 \\
Xh & 18 & 54 & 22 & 1 & 3 & 2 & 72 & 24 & 1 & 2 & 1 \\
Xk,Yk & 55 & 13 & 16 & 11 & 3 & 2 & 76 & 7 & 14 & 2 & 1 \\
X1,Y1 & 43 & 20 & 20 & 7 & 7 & 2 & 69 & 23 & 5 & 2 & 1 \\
Xt & 20 & 50 & 21 & 3 & 5 & 1 & 16 & 78 & 4 & 1 & 1 \\
Xy,Yy & 27 & 18 & 40 & 8 & 7 & 0 & 54 & 25 & 15 & 0 & 6 \\
Zg & 16 & 33 & 24 & 21 & 5 & 0 & 45 & 25 & 18 & 0 & 13 \\
Zo & 30 & 6 & 46 & 11 & 7 & 1 & 32 & 41 & 21 & 1 & 6 \\
Zt & 25 & 33 & 25 & 10 & 6 & 0 & 22 & 65 & 12 & 0 & 1 \\
SD & 49 & 9 & 26 & 1 & 14 & 1 & 91 & 6 & 1 & 1 & 1 \\
ST & 39 & 4 & 26 & 29 & 1 & 1 & 4 & 1 & 74 & 1 & 21 \\
\hline
\end{tabular}

Table 2a. The fraction of dust aerosol mass contributed by the soil clay and silt fractions for each of the four particle size bins for the bulk aerosol scheme in CAM4 from work by Kok (2011).

\begin{tabular}{lllll}
\hline $\begin{array}{l}\text { Particle } \\
\text { size bin }\end{array}$ & $\begin{array}{l}\text { Lower bin limit } \\
D_{\mathrm{p}}(\mu \mathrm{m})\end{array}$ & $\begin{array}{l}\text { Upper bin limit } \\
D_{\mathrm{p}}(\mu \mathrm{m})\end{array}$ & $\begin{array}{l}\text { Fraction of aerosol mass } \\
\text { from soil clay fraction }\end{array}$ & $\begin{array}{l}\text { Fraction of aerosol mass } \\
\text { from soil silt fraction }\end{array}$ \\
\hline 1 & 0.1 & 1 & 1 & 0 \\
2 & 1 & 2.5 & 0.970 & 0.030 \\
3 & 2.5 & 5 & 0.625 & 0.375 \\
4 & 5 & 10 & 0.429 & 0.571 \\
\hline
\end{tabular}

ble 1). In addition to renormalizing the soil types, hematite was added to the clay fraction $(0-2 \mu \mathrm{m})$ with the same proportion as prescribed in the silt fraction $(2-50 \mu \mathrm{m})$ by subtracting the required fraction from illite (Balkanski et al., 2007).

Mineralogy was mapped on FAO/UNESCO WGB84 at $5^{\prime} \times 5^{\prime}$ arc minutes with soil legend from FAO/UNESCO Soil Map of the World (1976) (Batjes, 1997). The corresponding mineral maps were regridded to model resolution $\left(2.5^{\circ} \times 1.9^{\circ}\right)($ Fig. 1). A nearest-neighbor algorithm was applied to estimate mineralogy of land mass not specified by the soils in Claquin's MMT to allow nonzero dust emissions in these regions. As described in more detail in the following section, the clay-sized soils $(0-2 \mu \mathrm{m})$ and silt-sized soils $(2-50 \mu \mathrm{m})$ are distributed in the four CAM4 bins and two
CAM5 modes following brittle fragmentation theory (Kok, 2011) (Table 2).

\subsection{Conversion of soil mineralogy to aerosol mineralogy}

We model the conversion of soil mineralogy to dust aerosol mineralogy for a given transport particle size bin by following the brittle fragmentation theory of dust emission (Kok, 2011). This theory predicts that the production of dust aerosols with size $D_{\mathrm{d}}$ is proportional to the volume fraction of soil particles with size $D_{\mathrm{s}} \leq D_{\mathrm{d}}$ according to Eq. (2): 
Table $2 \mathbf{b}$. The fraction of dust aerosol mass contributed by the soil clay and silt fractions for each of the two particle modes for the modal aerosol scheme in CAM5 from work by Kok (2011).

\begin{tabular}{lllll}
\hline $\begin{array}{l}\text { Particle } \\
\text { mode }\end{array}$ & $\begin{array}{l}\text { Lower bin } \\
\text { limit } D_{\mathrm{p}}(\mu \mathrm{m})\end{array}$ & $\begin{array}{l}\text { Upper bin } \\
\text { limit } D_{\mathrm{p}}(\mu \mathrm{m})\end{array}$ & $\begin{array}{l}\text { Fraction of aerosol mass } \\
\text { from soil clay fraction }\end{array}$ & $\begin{array}{l}\text { Fraction of aerosol mass } \\
\text { from soil silt fraction }\end{array}$ \\
\hline 1 & 0.1 & 1 & 1 & 0 \\
2 & 1 & 10 & 0.695 & 0.305 \\
\hline
\end{tabular}
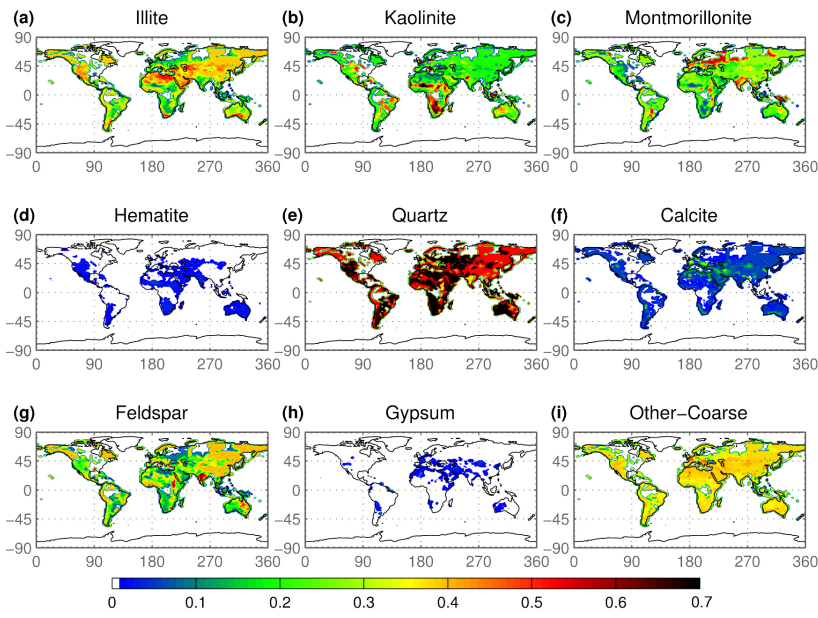

Figure 1. Mineral maps for CAM4 and AM5 based on work by Claquin et al. (1999) and Nicovic et al. (2011). Illite (a), kaolinite (b) and montmorillonite (c) are clay-sized $(0-2 \mu \mathrm{m})$. Hematite (d) has the same distribution for both clay-sized and siltsized (2-20 $\mu \mathrm{m})$. Quartz (e), calcite (f), feldspar (g), gypsum (h) and other coarse (i) are silt-sized. CAM4 includes illite (a), kaolinite (b), montmorillonite (c), hematite (d), quartz (e), calcite (f), feldspar (g) and gypsum (h). CAM5 includes illite (a), kaolinite (b), montmorillonite (c), hematite (d) and other coarse (i), which represents quartz, calcite, feldspar and gypsum.

$\frac{d V}{d D_{\mathrm{d}}} \propto \int_{0}^{D_{\mathrm{d}}} P_{\mathrm{s}}\left(D_{\mathrm{s}}\right) d D_{\mathrm{s}}$

where $V$ is the normalized volume of dust aerosols with size $D_{\mathrm{d}}$ and $P_{\mathrm{S}}\left(D_{\mathrm{s}}\right)$ is the particle size distribution of fully disaggregated soil particles. For a mineralogy data set with clay (0-2 $\mu \mathrm{m}$ diameter) and silt (2-50 $\mu \mathrm{m}$ diameter) soil fractions, we use Eq. (2) to convert from soil mineralogy to dust aerosol mineralogy. More specifically, for a given aerosol with size $D_{\mathrm{d}}$ the mass fraction originating from the soil clay and silt particle fractions are given by Eq. (3a) and 3b, respectively:

$$
\begin{gathered}
f_{\text {clay }}\left(D_{\mathrm{d}}\right)=\int_{0}^{D_{\text {clay }}} P_{\mathrm{s}}\left(D_{\mathrm{s}}\right) d D_{\mathrm{s}} / \int_{0}^{D_{\mathrm{d}}} P_{\mathrm{s}}\left(D_{\mathrm{s}}\right) d D_{\mathrm{s}}, \\
f_{\text {silt }}\left(D_{\mathrm{d}}\right)=\int_{D_{\text {clay }}}^{D_{\mathrm{d}}} P_{\mathrm{s}}\left(D_{\mathrm{s}}\right) d D_{\mathrm{s}} / \int_{0}^{D_{\mathrm{d}}} P_{\mathrm{s}}\left(D_{\mathrm{s}}\right) d D_{\mathrm{s}},
\end{gathered}
$$

where $D_{\text {clay }}=2 \mu \mathrm{m}, f_{\text {clay }}+f_{\text {silt }}=1$ and $D_{\mathrm{d}}>D_{\text {clay }}$. When $D_{\mathrm{d}}<D_{\text {clay }}, f_{\text {clay }}=1$ and $f_{\text {silt }}=0$. The integrals in Eq. $(3 \mathrm{a}, \mathrm{b})$ are evaluated by assuming that the size distribution of fully disaggregated soil particles follows a lognormal distribution (Kolmogorov, 1941) according to Eq. (4):

$P_{\mathrm{s}}\left(D_{\mathrm{s}}\right)=\frac{1}{D_{\mathrm{s}} \sqrt{2 \pi} \ln \left(\sigma_{\mathrm{s}}\right)} \exp \left\{-\frac{\ln ^{2}\left(D_{\mathrm{s}} / \overline{D_{\mathrm{s}}}\right.}{2 \ln ^{2}\left(\sigma_{\mathrm{s}}\right)}\right\}$,

where $\overline{D_{\mathrm{s}}}$ is the median diameter by volume and $\sigma_{\mathrm{s}}$ is the geometric standard deviation. Measurements of the particle size distribution of arid soil indicate that $\overline{D_{\mathrm{s}}} \approx 3.4 \mu \mathrm{m}$ and $\sigma_{\mathrm{s}} \approx 3.0$ for fully disaggregated soil particles with diameters smaller than $20 \mu \mathrm{m}$ (Kok, 2011). Combining Eqs. (3) and (4) yields

$$
\begin{aligned}
& f_{\text {clay }}\left(D_{\mathrm{d}}\right)=\frac{1+\operatorname{erf}\left[\frac{\ln \left(D_{\text {clay }} / \overline{D_{\mathrm{s}}}\right)}{\sqrt{2} \ln \left(\sigma_{\mathrm{s}}\right)}\right]}{1+\operatorname{erf}\left[\frac{\ln \left(D_{\mathrm{d}} / \overline{D_{\mathrm{s}}}\right)}{\sqrt{2} \ln \left(\sigma_{\mathrm{s}}\right)}\right]}, \\
& f_{\text {silt }}\left(D_{\mathrm{d}}\right)=\frac{\operatorname{erf}\left[\frac{\ln \left(D_{\mathrm{d}} / \overline{D_{\mathrm{s}}}\right)}{\sqrt{2} \ln \left(\sigma_{\mathrm{s}}\right)}\right]-\operatorname{erf}\left[\frac{\ln \left(D_{\text {clay }} / \overline{D_{\mathrm{s}}}\right)}{\sqrt{2} \ln \left(\sigma_{\mathrm{s}}\right)}\right]}{1+\operatorname{erf}\left[\frac{\ln \left(D_{\mathrm{d}} / \overline{D_{\mathrm{s}}}\right)}{\sqrt{2} \ln \left(\sigma_{\mathrm{s}}\right)}\right]} .
\end{aligned}
$$

To obtain the fraction of dust aerosol mass originating from the soil's clay and silt fractions for a given particle size bin, Eq. (5a) and (5b) are integrated over the bin's size boundaries and weighted by the sub-bin distribution as follows:

$$
\begin{aligned}
f_{\text {clay }, \text { bin }}= & \int_{D_{-}}^{D_{+}} f_{\text {clay }}\left(D_{\mathrm{d}}\right) \frac{d V}{d D_{\mathrm{d}}} d D_{\mathrm{d}} / \int_{D_{-}}^{D_{+}} \frac{d V}{d D_{\mathrm{d}}} d D_{\mathrm{d}}, \\
f_{\text {silt, bin }}= & \int_{D_{-}}^{D_{+}} f_{\text {silt }}\left(D_{\mathrm{d}}\right) \frac{d V}{d D_{\mathrm{d}}} d D_{\mathrm{d}} / \int_{D_{-}}^{D_{+}} \frac{d V}{d D_{\mathrm{d}}} d D_{\mathrm{d}},
\end{aligned}
$$

where $D_{-}$and $D_{+}$are the lower and upper bin size limits and $d V / d D_{\mathrm{d}}$ is the sub-bin dust size distribution by volume. 
As previously stated, the sub-bin size distribution in CAM follows a lognormal distribution with mass median diameter of $3.5 \mu \mathrm{m}$ and geometric standard deviation of 2.0 (Zender et al., 2003; Reid et al., 2003). We use Eqs. (4)-(6) to calculate the contribution of the silt and clay soil fractions to each of the four dust aerosol size bins used by CAM4 (Table 2a) and each of the two modes used by CAM5 (Table $2 b$ ).

\subsection{Modeling of radiation}

Radiation in CAM4 is parameterized using the deltaEddington approximation (Joseph et al., 1976; Coakley Jr et al., 1983) to determine the reflectivity and transmissivity for each of 19 shortwave spectral intervals at each vertical layer in the atmosphere. The vertical layers at a given spectral interval are combined to account for scattering between layers, allowing for the computation of upward and downward fluxes between each layer once per model hour. The optical properties for each aerosol species including extinction and single scattering albedo in solar short wavelengths (SWs) are calculated offline from species refractive indices with a Mie solver (Wiscombe, 1980) by integrating the extinction and scattering efficiencies over the size distribution of aerosol surface area. The mineral species whose SW optical properties have been derived from their respective refractive indices are illite, kaolinite, montmorillonite and hematite (Table 3), with the remaining mineral species - quartz, gypsum, feldspar and calcite - being represented by a "rest-of-dust" blend with optics calculated with Maxwell-Garnett (Niklasson et al., 1981) mixing of $48 \%$ quartz, $25 \%$ illite, $25 \%$ montmorillonite and $2 \%$ calcite by volume (C. Zender, personal communication, 2013). The wavelength-dependent complex refractive indices for all eight minerals along with the rest-of-dust blend ("Zender", Table 3) with (Mahowald et al., 2006) and without hematite (this study) are provided in the Supplement (Sect. S2). The density of each mineral is explicitly included ( $\rho_{\text {illite }}$ $=2750 \mathrm{~kg} \mathrm{~m}^{-3}, \rho_{\text {kaolinite }}=2600 \mathrm{~kg} \mathrm{~m}^{-3}, \rho_{\text {montmorillonite }}=$ $2350 \mathrm{~kg} \mathrm{~m}^{-3}, \rho_{\text {quartz }}=2660 \mathrm{~kg} \mathrm{~m}^{-3}, \rho_{\text {calcite }}=2710 \mathrm{~kg} \mathrm{~m}^{-3}$, $\rho_{\text {hematite }}=5260 \mathrm{~kg} \mathrm{~m}^{-3}, \rho_{\text {feldspar }}=2560 \mathrm{~kg} \mathrm{~m}^{-3}, \rho_{\text {gypsum }}=$ $2300 \mathrm{~kg} \mathrm{~m}^{-3}$ ), while the density of the rest-of-dust blend is $2500 \mathrm{~kg} \mathrm{~m}^{-3}$. Hygroscopicity for all minerals as well as the dust blend is prescribed at 0.068 . While different mineral species have unique water uptake abilities and thus different hygroscopicities, we assume the effect on the optical properties is small compared to other factors influencing our estimate of radiative forcing, and examining the CCN/IN capabilities of minerals was beyond the scope of this study. Not all the mineral species were modeled optically because the number of mineral species included in CAM5 differs from CAM4. Thus we only include the optical properties for minerals common to both atmosphere models. A method for calculating optical properties at infrared wavelengths (LWs) was not available at the time of the simulations. In CAM4, the LW aerosol effects are ignored in the release version, and are generally very difficult to calculate accurately, which is one of the many advantages of the new radiation scheme inside CAM5. We do not have a method to calculate the LW optics in CAM4, so we have to use the LW optics from CAM3 (Mahowald et al., 2006). In place of LW optical properties for the minerals, CAM3 optics were derived from refractive indices of a dust blend provided by Zender (Mahowald et. al., 2006) assuming Maxwell-Garnett mixing of $47.6 \%$ quartz, $25 \%$ illite, $25 \%$ montmorillonite, $2 \%$ calcite and $0.4 \%$ hematite by volume with density equal to $2500 \mathrm{~kg} \mathrm{~m}^{-3}$ and hygroscopicity prescribed at 0.14 . The error associated with this assumption is difficult to assess but may be quite large since the different minerals have very different optical properties in the longwave.

Radiation in CAM5.1 is parameterized with Rapid Radiative Transfer Model for GCM (RRTMG) (Liu et al., 2012; Iacono et al., 2008) with 14 and 16 spectral bands in SWs and LWs, respectively. Mineral optical properties are parameterized by wet refractive index and wet surface mode radius, with the wet refractive index estimated using the volume mixing rule for all components including water, and the wet radius estimated from the dry radius, relative humidity and volume mean hygroscopicity using Kohler theory (Ghan and Zaveri, 2007). Since this parameterization only utilizes refractive indices, the LW absorption parameters were generated. Flux calculations are done once per model hour for shortwave and longwave flux during model day $\left(\cos \left(\theta_{0}\right)>0\right)$.

The direct radiative forcing from dust for all simulations is determined by calculating the radiative forcing twice at each time step, one time through with all aerosol species and an additional time through with everything but dust or minerals, recalculating the wet size and volume mean refractive index without mineral dust. Both atmosphere models neglect scattering at LWs and only account for absorption in LWs for mineral aerosols, which may underestimate radiative forcing at the top of the atmosphere and surface by up to 50 and $15 \%$, respectively (Dufresne et al., 2002).

CAM5 was modified to include five mineral tracers for each of the two modes, four minerals and an additional tracer to carry the rest of dust. As previously mentioned, neglecting the radiative properties of the additional minerals in CAM4 facilitated a comparison between CAM4 and CAM5. In effect, we have a few extra diagnostic traces in our CAM4 simulation with mineralogy, which do not impact the simulation, and can use these in the mineralogical comparisons. However, their optical properties are identical to the rest-of-dust tracer in CAM5 and do not impact the radiative forcing differently.

\subsection{Description of simulations}

The cases simulated for both CAM4 and CAM5 are listed in Table 4. CAM4-d and CAM5-d simulations use dust from release versions of CAM4 and CAM5 in the CESM. CAM4-t and CAM5-t simulations consist of a variety of optimizations 
Table 3. Refractive indices of minerals used, wavelengths of refractive indices and references for input into CAM4 and CAM5. Refractive indices specified as "Zender" are a Maxwell-Garnet internal mixture of $48 \%$ quartz, $25 \%$ illite, $25 \%$ montmorillonite and $2 \%$ calcite by volume. These were used primarily to simplify the comparison between CAM4 and CAM5. Longwave optics from CAM3 (Mahowald et al., 2006) were substituted for CAM4 as a solver was not available to calculate the LW absorption coefficients from the refractive indices.

\begin{tabular}{lllcc}
\hline Minerals & Refractive indices & Wavelengths & CAM4 & CAM5 \\
\hline Illite & Egan and Hilgeman (1979) & 0.19 to $2.5 \mu \mathrm{m}$ & $\mathrm{X}$ & $\mathrm{X}$ \\
& Querry (1987) & 2.5 to $50.0 \mu \mathrm{m}$ & $\mathrm{X}$ & $\mathrm{X}$ \\
Kaolinite & Egan and Hilgeman (1979) & 0.19 to $2.5 \mu \mathrm{m}$ & $\mathrm{X}$ & $\mathrm{X}$ \\
& Querry (1987) & 2.5 to $50.0 \mu \mathrm{m}$ & $\mathrm{X}$ & $\mathrm{X}$ \\
Montmorillonite & Egan and Hilgeman (1979) & 0.19 to $2.5 \mu \mathrm{m}$ & $\mathrm{X}$ & $\mathrm{X}$ \\
& Querry (1987) & 2.5 to $50.0 \mu \mathrm{m}$ & $\mathrm{X}$ & $\mathrm{X}$ \\
Quartz & Zender & 0.2 to $40.0 \mu \mathrm{m}$ & $\mathrm{X}$ & \\
Calcite & Zender & 0.2 to $40.0 \mu \mathrm{m}$ & $\mathrm{X}$ & \\
Hematite & A. H. M. J. Triaud & 0.1 to $40.7 \mu \mathrm{m}$ & $\mathrm{X}$ & $\mathrm{X}$ \\
Feldspar & Zender & 0.2 to $40.0 \mu \mathrm{m}$ & $\mathrm{X}$ & \\
Gypsum & Zender & 0.2 to $40.0 \mu \mathrm{m}$ & $\mathrm{X}$ & \\
Dust - other & Zender & 0.2 to $40.0 \mu \mathrm{m}$ & & $\mathrm{X}$ \\
\hline
\end{tabular}

Table 4. Description of the model simulations used in this study. All cases are 8-year simulations, with the last 6 years used for analysis. All cases are run at $1.9^{\circ} \times 2.5^{\circ}$ resolution. FSDBAM indicates CAM4 physics, bulk aerosols, active atmosphere, land and sea ice components, data ocean, slab glacier and GEOS5 meteorology. FC5 indicates CAM5 physics, modal aerosols, stand-alone atmosphere with land and sea ice components, data ocean, slab glacier and GEOS5 meteorology. Default, tuned and tuned plus mineralogy cases are listed in the upper portion of the table, and the lower portion of the table designates the simulations part of the sensitivity study section. The suffix "-m" refers to the prescription of hematite from both fine and coarse soil fractions, while the suffix "-mH" refers to hematite prescribed solely from the fine soil fraction.

\begin{tabular}{llll}
\hline Case & Configuration & $\begin{array}{l}\text { Emission size } \\
\text { distribution }\end{array}$ & Optics \\
\hline CAM4-d & FSDBAM & release & release \\
CAM4-t & FSDBAM & Kok (2011) & tuned \\
CAM4-m & FSDBAM & Kok (2011) & Table 3 \\
CAM5-d & FC5 & release & release \\
CAM5-t & FC5 & Kok (2011) & tuned \\
CAM5-m & FC5 & Kok (2011) & Table 3 \\
CAM4-trs & FSDBAM & release & tuned \\
CAM4-mH & FSDBAM & Kok (2011) & Table 3 \\
CAM5-trs & FC5 & release & tuned \\
CAM5-mH & FC5 & Kok (2011) & Table 3 \\
\hline
\end{tabular}

from the default versions to better simulate observed dust emission, transport, depositional fluxes and optical properties. The tuning consists of optimized soil erodibility maps for each model (Mahowald et al., 2006; Albani et al., 2014), emission particle size distribution following brittle fragmentation theory (Kok, 2011), increased solubility for dust, increased cloud scavenging coefficients (Albani et al., 2014) and improved optical properties. The improved optical prop- erties in CAM4 include SW extinction and scattering coefficients derived from the refractive indices from MaxwellGarnett mixing of $47.6 \%$ quartz, $0.4 \%$ hematite, $25 \%$ illite, $25 \%$ montmorillonite and $2 \%$ calcite by volume, with density equal to $2500 \mathrm{~kg} \mathrm{~m}^{-3}$ and hygroscopicity equal to 0.068, and CAM3 LW absorption coefficients (Mahowald et al., 2006) computed from refractive indices with MaxwellGarnett mixing of $47.6 \%$ quartz, $25 \%$ illite, $25 \%$ montmorillonite, $2 \%$ calcite and $0.4 \%$ hematite by volume, with density equal to $2500 \mathrm{~kg} \mathrm{~m}^{-3}$ and hygroscopicity prescribed at 0.14 . The inclusion of the CAM3 LW absorption coefficients is a marked improvement in physical processes from release dust (CAM4-d), which has zero LW optics (Yoshioka et al., 2007). The optimized optical properties in CAM5 include extinction, scattering and absorption parameterizations derived from the wet particle mode radius and refractive indices from Maxwell-Garnett mixing of $47.6 \%$ quartz, $0.4 \%$ hematite, $25 \%$ illite, $25 \%$ montmorillonite and $2 \%$ calcite by volume, with density equal to $2500 \mathrm{~kg} \mathrm{~m}^{-3}$ and hygroscopicity equal to 0.068 . The tuning parameterizations are described in detail in Albani et al. (2014) and were used for both tuned and mineralogy runs in CAM4 and CAM5. The only change from the default release for CAM we tested explicitly was the particle size distribution at emission (Kok, 2011). CAM4-m and CAM5-m simulations employ the same tuning parameterizations as the tuned cases, except the optical properties (extinction and scattering for CAM4, extinction, scattering and absorption for CAM5) are derived from the mineral refractive indices (Table 3), and the emissions are scaled by the mineral maps described in Sects. 2.1 and 2.2 (Fig. 1). Two sensitivity studies are also undertaken in order to quantify the importance of including mineralogy in place of dust in a global model for RF calculations. The studies involve characterizing the sensitivity of dust RF to the size distribution at emission (CAM4-trs, CAM5-trs) and to the 
Table 5. Observations of mineralogy used to evaluate simulated mineral distributions in CAM4 and CAM5. Near-surface observational data were chosen in order to compare to near-surface mineral concentrations in the models. Ocean core sediment data are compared to bulk dry and wet deposition.

\begin{tabular}{lllll}
\hline Reference & Location & Type of data & Month & Type \\
\hline Biscaye 1965 & Atlantic Ocean & Sediment & N/A & K / I \\
Cacquineau et al. 1998 & Tropical North Atlantic & Suspended $(<20 \mathrm{~m})$ Ratio & April & K / I \\
Falkovich et al. (2001) & Israel & Suspended $(<20 \mathrm{~m})$ ratio & March & K / I; C / Q; F / Q \\
Glaccum and Prospero 1980 & Tropical North Atlantic & Suspended (<20 m) ratio & Aug. & K / I; C / Q; F / Q \\
Kandler et al. (2009) & Morocco & Suspended (<20 m) ratio, & May & K / I; H / I; C / Q; F / Q; \\
& & volume fraction & & H / Q; I, K, Q, C, H, F, G \\
Kiefert et al. (1996) & Charleville, AUS & Suspended (<20 m) ratio & Dec & K / I \\
Prospero and Bonatti 1969 & Equitorial Pacific & Suspended (<20 m) ratio & FMA & K / I; F / Q \\
Shen et al. (2005) & N. China & Suspended $(<20 \mathrm{~m})$ ratio & MAM & K / I \\
Shi et al. (2005) & Beijing & Suspended $(<20 \mathrm{~m})$ ratio & March & C / Q; F / Q; H / Q \\
\hline
\end{tabular}

soil size distribution of hematite (CAM4-mH, CAM5-mH). For the first sensitivity study, the tuning parameterizations for dust in both CAM4 and CAM5 are kept constant, except the new size distribution was replaced with the size distribution in the release version of the model with mass fractions of 3.8, 11.1, 17.2 and $67.8 \%$ for bins 1-4 (CAM4-trs) and mass fraction of 3.2 and $96.8 \%$ for modes 1 and 3 (CAM5trs). Note that hematite in the models is treated in both fine and coarse modes as the particle size distribution of hematite may differ from the Claquin et al. (1999) MMT case where hematite was prescribed solely in the coarse mode (CAM4$\mathrm{m}$, CAM5-m). While it was acknowledged that the available data on hematite were very limited, recent observations suggest that hematite is predominantly in the smaller, clay-sized range. Cwiertney et al. (2008) find much higher relative iron concentrations in particles $<0.75 \mu \mathrm{m}$ diameter. Higher iron concentrations indicate iron-rich oxides/hydroxides as opposed to iron substitutions in silicate clay lattices, which are typically quite small (Journet et al., 2008). The second study is designed to test the sensitivity of the soil size distribution of hematite and retains all parameterizations for the mineralogy runs with the exception of removing hematite from the silt-sized soil maps and scaling up the remaining silt-sized minerals (CAM4-mH and CAM5-mH). All the simulations use GEOS-5 reanalysis meteorology and were run from 2004 to 2011, with the last 6 years (2006-2011) used for analysis.

\subsection{Comparison to observations}

The following sections describe the comparison of mineralogy to in situ field measurements as well as ocean core sediment data (Table 5). Distinguishing natural mineral aerosol is complicated by atmospheric mixing with anthropogenic aerosols and other natural aerosols, as well as the distance between the dust source and the location of the observations (Claquin et al., 1999; Kalashnikova and Kahn, 2008). Additionally, ocean sediment measurements are complicated by complex ocean circulation patterns (Han et al., 2008; Siegel and Deuser, 1997). A wide variety of methods are used for dust sample collection; this can impact measuring concentrations of smaller or highly aspherical particles (Reid et al., 2003), the non-uniformity of which further complicates the model verification process. As a way to compare observed mineralogy where particle size distribution is not explicitly reported, the mass ratios of minerals with similar diameters are compared to the mass ratios of observed mineralogy (Claquin et al., 1999).

The mixing ratio of minerals near the surface in CAM4 and CAM5 is compared to the only available observation (Kandler et al., 2009) of relative mineral volume abundance as a function of mean particle diameter (Fig. 4). Kandler et al. (2009) report mineral fractions with particle diameters that do not match the modeled particle diameter for bin 1 in CAM4 and modes 1 and 3 in CAM5. To compare the observed mineral fractions to the model, after converting observed volume fractions to mass fractions, the average mass abundance for CAM4 bin 1 was related to particle diameters 0.16, 0.35 and $0.71 \mu \mathrm{m}$ (Eqs. 7 and 8).

$\bar{\gamma} \rho=\frac{\int_{0.1}^{D_{1,+}} \frac{d V}{d D_{\mathrm{d}}} \gamma_{1} d D_{\mathrm{d}}+\int_{D_{2,-}}^{D_{2,+}} \frac{d V}{d D_{\mathrm{d}}} \gamma_{2} d D_{\mathrm{d}}+\int_{D_{3,-}}^{1} \frac{d V}{d D_{\mathrm{d}}} \gamma_{3} d D_{\mathrm{d}}}{\int_{0.1}^{1} \frac{d V}{d D_{\mathrm{d}}} d D_{\mathrm{d}}}$,

where

$\frac{d V}{d D_{\mathrm{d}}}=\frac{1}{c_{\mathrm{w} 2 v}}\left[1+\operatorname{erf}\left(\frac{\ln \left(D_{\mathrm{d}} / \overline{D_{\mathrm{s}}}\right)}{\sqrt{2} \ln \left(\sigma_{\mathrm{s}}\right)}\right)\right] \exp \left[-\left(\frac{D_{\mathrm{d}}}{\lambda}\right)^{3}\right]$.

The upper and lower diameters are the middle of the particle diameters reported in Kandler et al. (2009): $D_{1,+}=D_{2,-}$ $=\left(D_{1} \times D_{2}\right)^{0.5}=0.24 \mu \mathrm{m} ; D_{2,+}=D_{3,-}=\left(D_{2} \times D_{3}\right)^{0.5}=$ $0.5 \mu \mathrm{m}$. V is the normalized volume of dust aerosols with size $D_{\mathrm{d}} ; c_{\mathrm{v}}=12.62 \mu \mathrm{m}$ is a normalization constant; $\rho$ is the density of a given mineral; and $\gamma_{1-3}$ are the observed volume fractions at $0.16,0.35$ and $0.71 \mu \mathrm{m}$, respectively. Equation (8) 
is the predicted size distribution at emission following brittle fragmentation theory (Kok, 2011). The size distribution at emission and the distribution observed for particles of diameters $<1.0 \mu \mathrm{m}$ are expected to be similar given the proximity of the measurements to the emission source as well as the negligible impact of gravitational settling. Particle diameters $1.6,3.5$ and $7.1 \mu \mathrm{m}$ correspond well with bins $2-4$, respectively. For CAM5, the accumulation mode was matched with the correlation for bin 1 , and the coarse mode average mass fraction of mineral species was estimated from Eqs. (9) and (10).

$\bar{\gamma} \rho=\frac{\int_{1}^{D_{1,+}} \frac{d V}{d D_{\mathrm{d}}} \gamma_{1} d D_{\mathrm{d}}+\int_{D_{2,-}}^{D_{2,+}} \frac{d V}{d D_{\mathrm{d}}} \gamma_{2} d D_{\mathrm{d}}+\int_{D_{3,-}}^{10} \frac{d V}{d D_{\mathrm{d}}} \gamma_{3} d D_{\mathrm{d}}}{\int_{1}^{10} \frac{d V}{d D_{\mathrm{d}}} d D_{\mathrm{d}}}$,

where

$\frac{d V}{d D_{\mathrm{d}}}=\left[0.5+0.5 \operatorname{erf}\left(\frac{\ln \left(D_{\mathrm{d}} / \overline{\left.D_{p g}\right)}\right.}{\sqrt{2} \ln \left(\sigma_{\mathrm{g}}\right)}\right)\right]$

is the size distribution at emission. The upper and lower diameters are the middle of the particle diameters reported in Kandler et al. (2009): $D_{1,+}=D_{2,-}=\left(D_{1} \cdot D_{2}\right)^{0.5}=$ $(1.6 \cdot 3.5)^{0.5}=2.4 \mu \mathrm{m} ; D_{2,+}=D_{3,-}=\left(D_{2} \cdot D_{3}\right)^{0.5}=$ $(3.5 \cdot 7.1)^{0.5}=5.0 \mu \mathrm{m}$.

Comparing the modeled distribution of minerals with observations that do not specify the particle size distribution is not very effective since there is a correlation between mineralogy for a given particle size distribution (Claquin et al., 1999). For this reason, the ratio of similarly sized minerals is compared. The following mineral ratios were chosen because they matched the similar size criterion and had at least five locations of observation. In the clay-size range, kaolinite to illite $(\mathrm{K} / \mathrm{I})$ is chosen because this comparison was possible for both CAM4 and CAM5. In the silt-size range, the following comparisons were made: calcite to quartz $(\mathrm{C} / \mathrm{Q})$ and feldspar to quartz (F/Q).

\section{Results}

\subsection{Desert dust mineralogical distribution}

The spatial distribution of minerals in aerosols in CAM4 and CAM5 are different (Figs. 2 and 3), and while the distributions of minerals in soils are identical for both models (Fig. 1), there are different physical parameterizations for aerosol advection and deposition between CAM4 and CAM5. In order to discuss the significance of the spatial distribution of mineralogy and to give credibility to the simulations, the modeled distributions are evaluated with available observational data (Table 5).
Because of the size segregation of minerals in the soil materials (Claquin et al., 1999), it is ideal to compare the modeled mineralogy by size distribution. However, there is limited size segregated data (Table 5; Fig. 4). For four of the seven minerals considered from Kandler et al. (2009) - illite (Fig. 4a), kaolinite (Fig. 4b), quartz (Fig. 4c) and feldspar (Fig. 4f) - the simulations for both CAM4 and CAM5 simulate dynamic range in mineral mass fraction with particle size, while the mass fractions observed are relatively constant with size. This is because in the simulations we assumed that the clay-sized minerals dominate the smaller size bins while the silt-sized minerals dominate the larger size bins. While the magnitude of gravitational settling for any given mineral is larger in the coarser bins, the relative mass for finer bins ( 1 and 2 ) is dominated by clay minerals and the relative mass for coarser bins ( 3 and 4 ) is dominated by silt-sized minerals. The proximity of the observation to the source of emission is another possible explanation for why the relative fractions sampled are constant with size, since transport and deposition have not significantly altered the mineral distributions at emission.

There is one instance of the range of variability of mass with size where the CAM4 simulation did not predict this variability for gypsum (Fig. 4g). In general, gypsum concentrations predicted from Claquin's MMT were very small (Figs. 1h, 2h), and this may cause a low bias in the model. However, Glaccum and Prospero (1980) reported gypsum crystallizing on collection plates, and it was hence not considered to have been part of the transported minerals observed during their field study. Given the discrepancies on how to measure gypsum concentrations along with atmospheric processing of gypsum (Glaccum and Prospero, 1980) that was not simulated in this study, the attempt to correlate gypsum observations with simulated gypsum concentrations is likely not very meaningful. Calcite (Fig. 4d) and hematite (Fig. 4e) are correlated with observations at this location, with hematite being most important for simulating the DRF in the shortwave, which is one of the primary goals of this study.

Next we compare the ratio of minerals available in the observations (Table 5). When comparing means between models and observations, we see a low bias in both models; however CAM5 more closely matches the mean of observations. In general, both CAM4 and CAM5 do not capture the dynamic range seen in the observations (Figures 5-8) when comparing monthly mean model output to the month the observations were made. For the comparison of kaolinite to illite, the mean observational ratio is $0.72 \pm 0.91$ compared to the mean ratios for CAM4 and CAM5 of $0.55 \pm 0.18$ and $0.63 \pm 0.28$, respectively. $\mathrm{K} / \mathrm{I}$ in CAM5 indicates some structure and range in possible values; however the sites of observation are all in the Northern Hemisphere, except for one site in Australia, limiting comparisons where CAM5 predicts greater range (Fig. 5). The daily averaged mineral ratios for all days simulated indicates temporal variability on the 

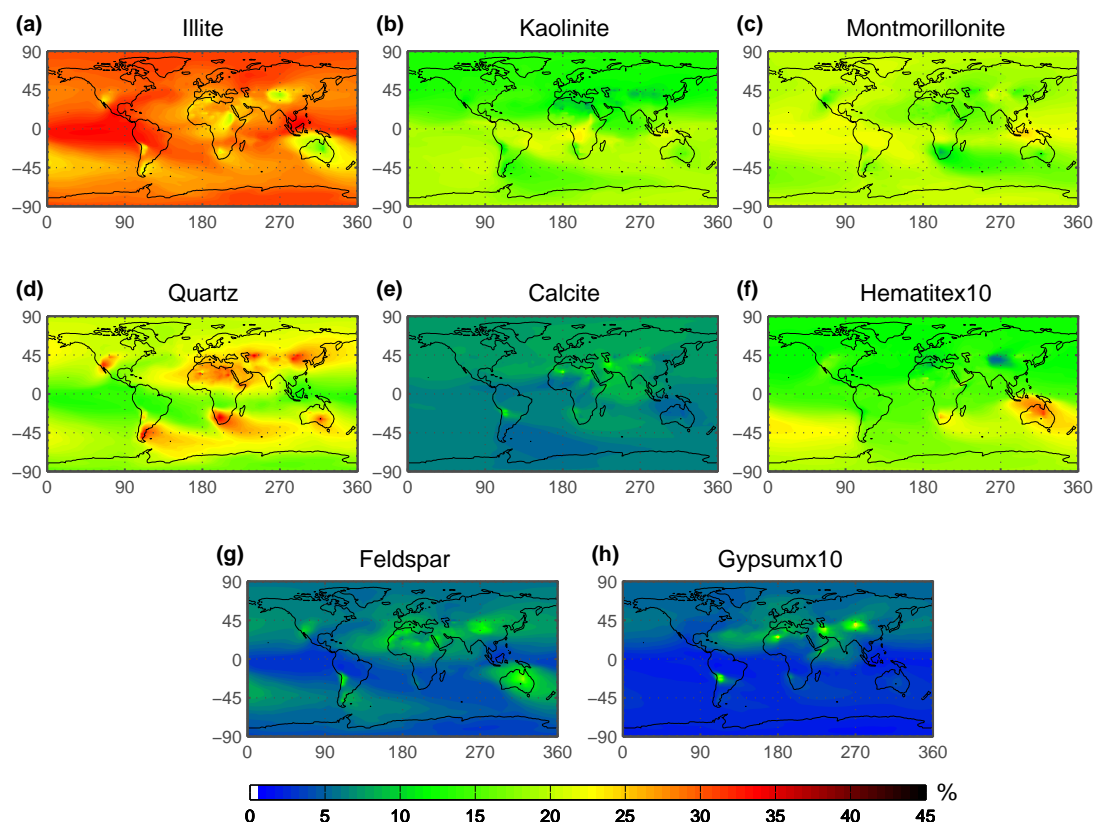

Figure 2. Total percent column mineral distributions for CAM4 shown as the sum of all four bins for each mineral. Hematite (f) and gypsum (h) are scaled by 10 so that they can be visually compared with illite (a), kaolinite (b), montmorillonite (c), quartz (d), calcite (e) and feldspar (g).
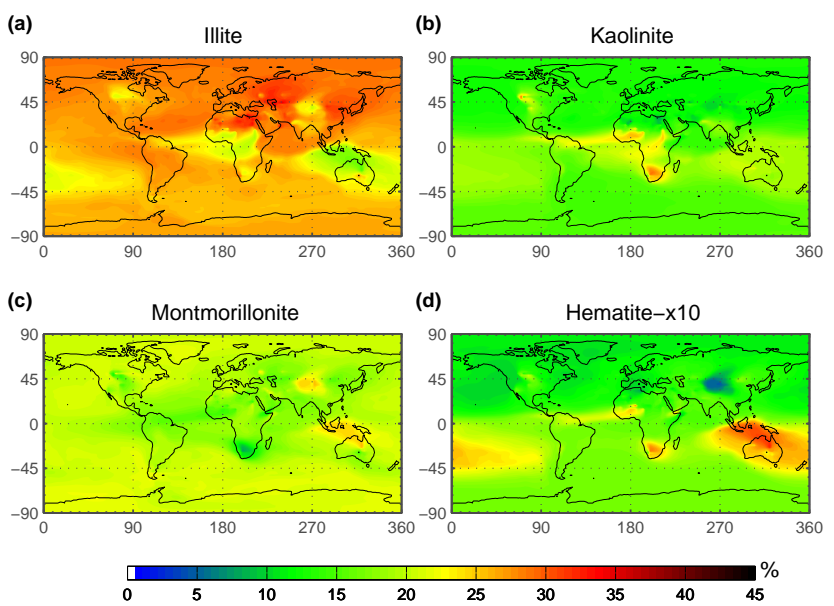

Figure 3. Total percent column mineral distributions for CAM5 shown as the sum of the fine mode (mode 1) and coarse mode (mode 3) for each mineral. Hematite (d) is scaled by 10 so that it can be visually compared with illite (a), kaolinite (b) and montmorillonite (c).

same order of magnitude as the variability in the observations, suggesting that temporal variability can be playing a significant role in the observed ratios. The silt-size mineral ratios are only compared for CAM4 since quartz is not explicitly modeled in CAM5 (Fig. 6). The mean in the observations for the ratios of calcite to quartz and feldspar to quartz are $0.56 \pm 0.26$ and $0.42 \pm 0.22$, respectively, and the means for CAM4 C / Q and F / Q are $0.32 \pm 0.08$ and $0.32 \pm 0.09$, respectively. Similarly to K / I, Figs. 7 and 8 indicate the inability of the model to capture the range of variability of observed ratios when comparing monthly means and some improvement when looking at daily averages.

Typically, dust samples from field studies are collected during a dust event over a period of 1-3 days. Since the observations were made at various time periods in the past, we have not simulated the exact days the observations occurred. Instead, we compare the model simulations' monthly means to the month the observations were made. Therefore, while the simulated monthly mineral ratios do not appear to have the range of variability from observations, this is likely at least partially an artifact of the smoothing effect from monthly averages. We see an increase in variability, particularly for CAM5 when examining the daily averaged mineral ratios for each day from 2006 to 2011 (Fig. 5).

Modeled mineral ratio K / I is compared to ocean core sediment mineralogy for CAM4 (Fig. 7) and CAM5 (Fig. 8) (Biscaye, 1965). The mean ratio in the data is $1.14 \pm 3.7$, and the mean ratio at the observation coordinates is the same for both CAM4 $(0.62 \pm 0.17)$ and CAM5 $(0.62 \pm 0.19)$, indicating an underestimate of mean and variability of this ratio in both models. The correlations for both models are quite poor overall, and the range in values for CAM5 is similar to CAM4, with $95 \%$ of data points falling between 0.4 and 1 , compared to CAM4 with a range of 0.4 to 0.95 . Note some resemblance of the spatial pattern of Biscaye's data (Figs. 7b, 8b) with CAM5 (Fig. 8a) around north Africa and eastern South America. The latitude band correlations for CAM4 and 

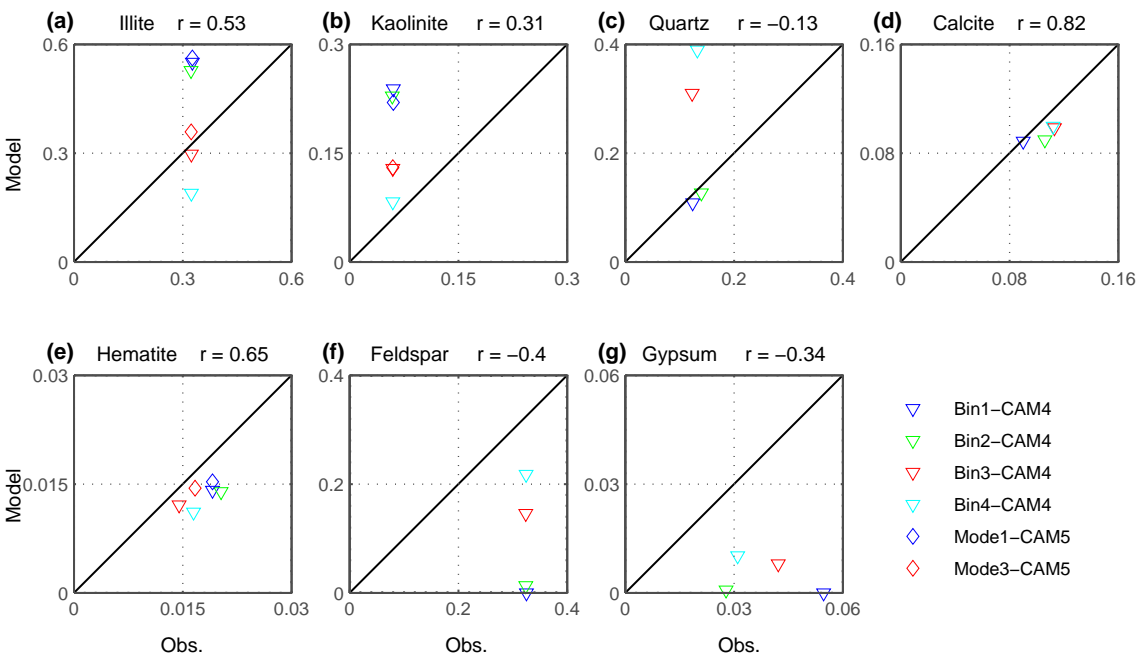

Figure 4. Relative mass abundance of minerals near the surface as modeled compared to observations from Kandler et al. (2009) for CAM4, bins 1-4, and CAM5, mode 1 and mode 3. The month of May was averaged from 2006 to 2011 for the models. The CAM4 comparison is for quartz (c), calcite (d), feldspar (f) and gypsum (g). Comparisons for CAM4 and CAM5 include illite (a), kaolinite (b) and hematite (e).
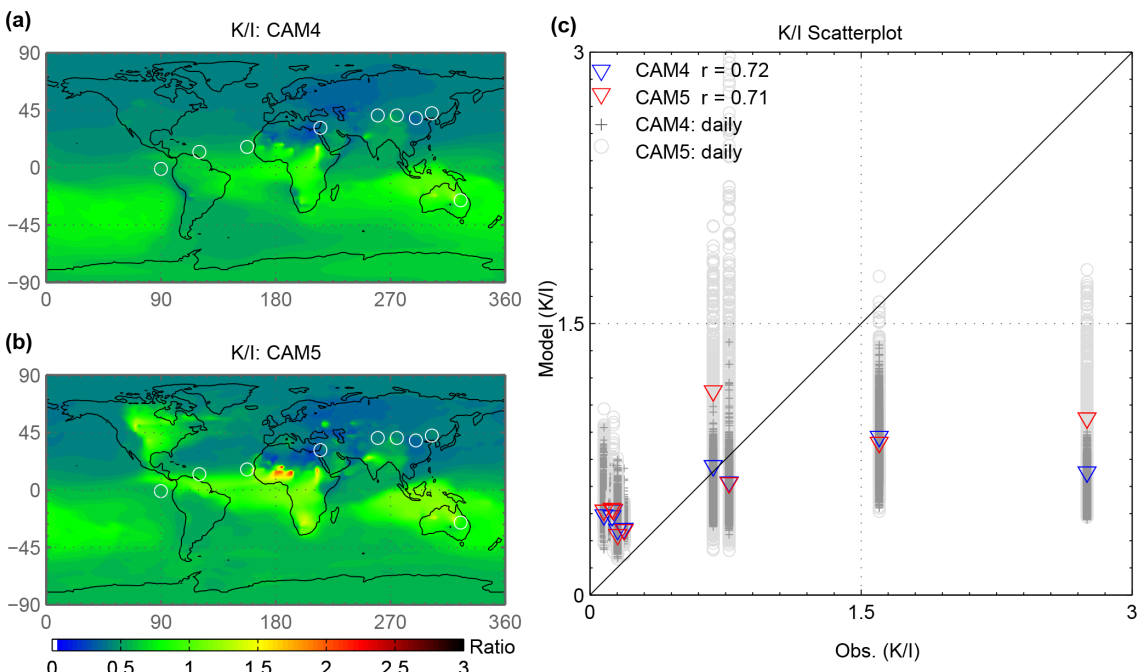

Figure 5. Kaolinite / illite mineral ratio of mineral concentrations near the surface from CAM4 and CAM5 (kg K / kg I) compared to bulk observational ratios (kg K / kg I) from fieldwork by Shen et al. (2005), Glaccum and Prospero (1980), Prospero and Bonatti (1969), Caquineau et al. (1998), Kiefert et al. (1996) and Falkovich et al. (2001). Colored values in (c) represent averages for the month in which the observations occurred, while the grey symbols represent daily averaged values over the course of the simulations (2006-2011).

CAM5 are poor, although CAM5 appears to have more variability along the Equator. While these figures do not capture the range in the data, the comparison is inherently difficult given ocean circulation of dust from deposition on the surface to sedimentation on the ocean floor that the simulated deposition distributions cannot be expected to capture (Han et al., 2008; Siegel and Deuser, 1997). This along with physical and chemical processing during atmospheric transport and sedimentation further hinder the comparison.

Summarizing the above comparisons, the mineralogical distributions simulated by the model do not have the dynamic range that the few available observations indicate. However, multiple factors are responsible, from differing timescales of observations to the atmospheric processing of dust that is not yet included in these models. When looking at daily averaged mineral ratios (Figs. 5-6), the temporal variability in the simulations indicates greater range than monthly means. In addition, there is likely to be sub-grid variability in the spatial distribution of mineralogy, which is not at all captured by the model. We also assume one mean mineralogical relationship to every soil type, which is an oversimplification. Interestingly, mineral ratios in most of the main desert soils 

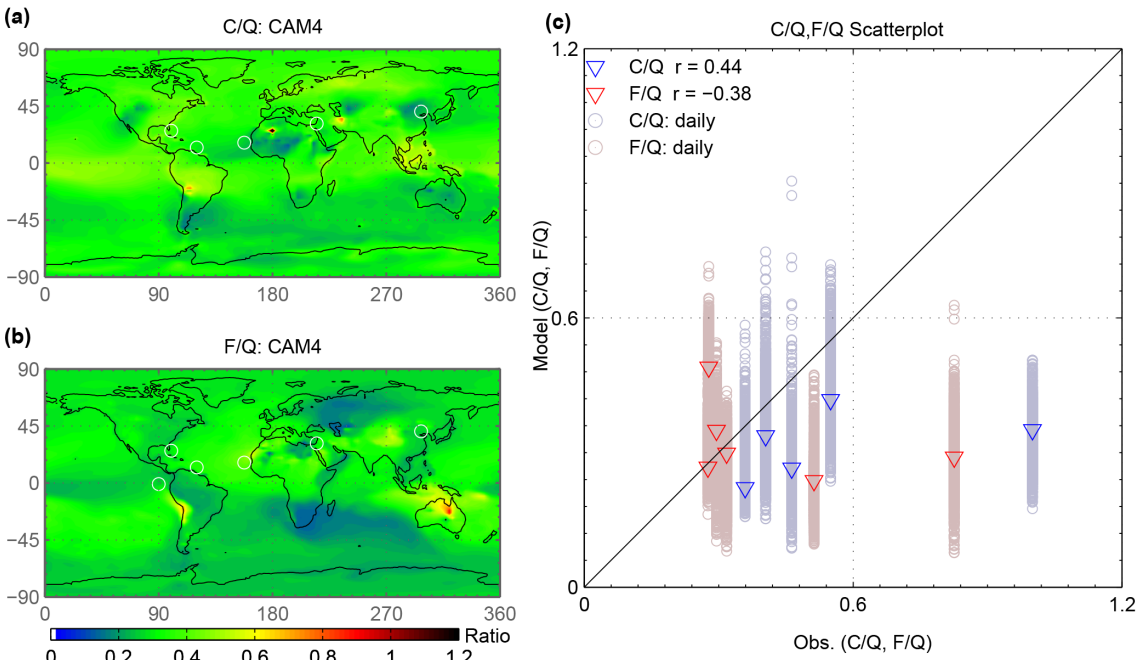

Figure 6. Calcite/quartz and feldspar / quartz mineral ratio comparison of mineral concentrations near the surface from CAM4 (e.g., $\mathrm{kg} \mathrm{C} \mathrm{/} \mathrm{kg} \mathrm{Q)} \mathrm{to} \mathrm{bulk} \mathrm{observational} \mathrm{ratios} \mathrm{from} \mathrm{fieldwork} \mathrm{by} \mathrm{Glaccum} \mathrm{and} \mathrm{Prospero} \mathrm{(1980),} \mathrm{Prospero} \mathrm{and} \mathrm{Bonatti} \mathrm{(1969),} \mathrm{Kiefert} \mathrm{et} \mathrm{al.} \mathrm{(1996),}$ Falkovich et al. (2001) and Shi et al. (2005). Bright blue and red symbols in (c) represent averages for the month in which the observations occurred, while the pale red and blue symbols represent daily averaged values over the course of the simulations (2006-2011).
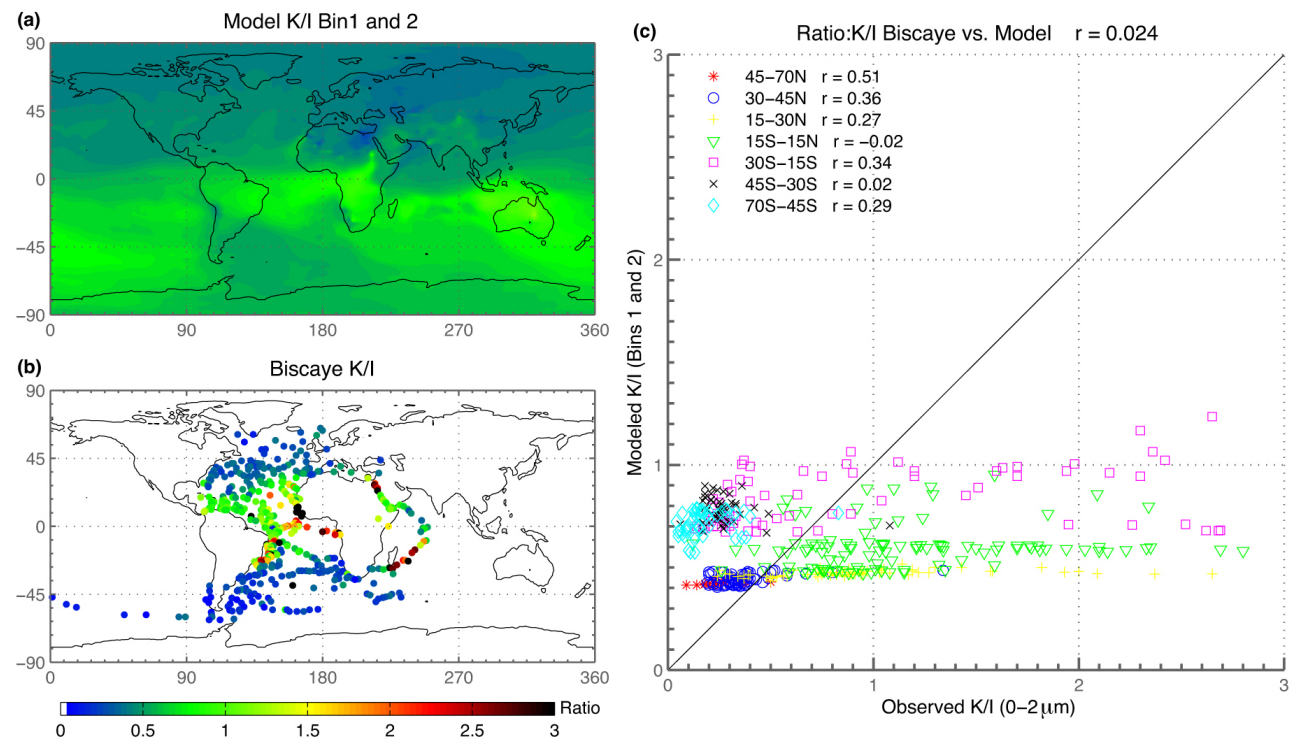

Figure 7. Kaolinite / illite mineral ratio of wet and dry deposition for bin 1 and bin 2 from CAM4 (a) (kg K / kg I) and from characteristic basal X-ray diffraction maxima ratios of K / I of ocean core sediments (b) (Biscaye, 1965). Data are segregated by latitude bands in scatterplot (c).

exhibit range of variability within the range of the observations of variability in mineral concentrations. This suggests that, in theory, the soil maps we are using could capture the observed ranges in mineral ratios. For example, the variability of the mineral ratio $\mathrm{K} / \mathrm{I}$ in north Africa is between about 0.2 and 5. Since there were more observations in this region accounted for in the mineral maps from Claquin et al. (1999), along with north Africa accounting for up to $80 \%$ of global dust emission, this heterogeneity is promising. However, due to the coarse resolution of the model, the mineral ratios in the simulations do not capture observations of mineral ratios in dust deposition or concentrations near the surface. In addition, the variability over desert regions in Australia is low (between 1 and 2), while in China nearly all grid boxes of soil mineralogy $\mathrm{K} / \mathrm{I}$ are around 0.5 , which suggests that the assumed soil mineral variabilities are not adequate in these regions. While in the model we include kaolinite and illite with the same assumed size distribution, in reality, kaolinite tends to be in a slightly larger size fraction than illite (0.5-4 and $0.1-1 \mu \mathrm{m}$, respectively) (Glaccum and Prospero, 1980). 
Table 6a. The mean and standard deviation for annually averaged AERONET (Holben et al., 1998, 2001) retrievals and the annually averaged means for CAM4 with untuned (default) dust (CAM4d), with tuned dust (CAM4-t) and with mineralogy (CAM4-m), for CAM5 with untuned dust (CAM5-d), with tuned dust (CAM5-t) and with mineralogy (CAM5-m) for aerosol optical depth (AOD), absorbing AOD and single scattering albedo (SSA) at $533 \mathrm{~nm}$ at AERONET sites where $\mathrm{AOD}_{\text {dust }}>0.5 \cdot \mathrm{AOD}_{\text {total }}$. The lower portion of the table lists the means for the sensitivity studies for CAM4 and CAM5 with tuned dust and release (default) size distribution (CAM4-trs, CAM5-trs) and for CAM4 and CAM5 mineralogy simulations with the source of hematite coming solely from the soil clay fraction (CAM4-mH, CAM5-mH).

\begin{tabular}{llll}
\hline & AOD & AAOD & SSA \\
\hline AERONET & 0.383 & 0.046 & 0.923 \\
SD & 0.115 & 0.011 & 0.013 \\
CAM4-d & 0.288 & 0.037 & 0.885 \\
CAM4-t & 0.214 & 0.015 & 0.935 \\
CAM4-m & 0.210 & 0.009 & 0.958 \\
CAM5-d & 0.274 & 0.037 & 0.887 \\
CAM5-t & 0.350 & 0.026 & 0.933 \\
\hline CAM5-m & 0.329 & 0.042 & 0.890 \\
CAM4-trs & 0.267 & 0.015 & 0.948 \\
CAM4-mH & 0.211 & 0.009 & 0.959 \\
CAM5-trs & 0.423 & 0.028 & 0.941 \\
CAM5-mH & 0.330 & 0.038 & 0.901 \\
\hline
\end{tabular}

So in the model these values will tend to stay constant as the model advects them downwind, while in reality these should be more fractionation occurring with transport. It is unclear how more resolution of the size fractions of the minerals in the soils would improve our simulations. As this study was a first attempt at modeling global mineralogy and was primarily dedicated to building the framework required to carry multiple mineral tracers as well as synching them with the radiation codes, a module to simulate physical and chemical fractionation and processing of minerals during emission and transport was not available for this study. Therefore, these simulations cannot be expected to capture all the observed mineral characteristics of dust deposited away from the source. For example, observations suggest that calcite concentrations in airborne dust are a function of the wind velocity that occurred during saltation, with the relative amount decreasing with increasing velocity (Caquineau et al., 1998; Gomes et al., 1990; Sabre et al., 1997), a process that is not included here. In addition, acidic processing of calcite to gypsum would also result in less calcite abundance in collected dust and an overall increase in the abundance of clay. In the future, improvements to the simulation of the distribution of mineralogy, especially to better capture the range of variability, are necessary.
Table 6b. The standard deviation in the model over the standard deviation in AERONET. Values less than 1 indicate that the model is not capturing the dynamic range from the observations, while values greater than 1 indicate the model is simulating a larger range than observed. This metric is used to test whether the simulations with mineralogy are better capturing the range in the observations, with italic font denoting an increase in ability and bold font denoting agreement with the range in AERONET.

\begin{tabular}{llll}
\hline & AOD & AAOD & SSA \\
\hline CAM4-d & 0.58 & 0.56 & 0.79 \\
CAM4-t & 0.50 & 0.31 & 0.59 \\
CAM4-m & 0.49 & 0.16 & 0.57 \\
CAM5-d & 0.75 & 1.13 & 1.03 \\
CAM5-t & $\mathbf{1 . 0 0}$ & 0.80 & 0.70 \\
\hline CAM5-m & 0.93 & 1.40 & 1.10 \\
CAM4-trs & 0.66 & 0.31 & 0.51 \\
CAM4-mH & 0.49 & 0.16 & 0.57 \\
CAM5-trs & 1.20 & 0.84 & 0.62 \\
CAM5-mH & 0.94 & 1.25 & 0.98 \\
\hline
\end{tabular}

\subsection{Aerosol optical depth and single scattering albedo}

Annually averaged aerosol optical depth (AOD), absorbing aerosol optical depth (AAOD) and single scattering albedo (SSA) (Holben et al., 1998, 2001; Dubovik and King, 2000; Dubovik et al., 2000) are simulated for each model at $533 \mathrm{~nm}$ and compared to annually averaged AERONET retrievals. AERONET sites were chosen in regions where the modeled $\mathrm{AOD}_{\text {dust }}>\mathrm{AOD}_{\text {total }} \times 0.5$ (at $533 \mathrm{~nm}$ ) to restrict the comparison to dust. The total AOD depends on the concentration of suspended aerosols and the degree to which they attenuate radiation. For both CAM4 and CAM5, the simulations with mineralogy have smaller values compared to the simulations with tuned dust at nearly every point (Fig. 9a, b); however both tuned and speciated cases agree with measurements of AOD much better than AAOD. This is due to the shortwave extinction coefficients for tuned dust having higher values than the extinction coefficients for each of the minerals. Both the simulations with tuned dust and with mineralogy are biased low and their range is about half that observed (Fig. 9a, b). The simulations with mineralogy perform worse than those with tuned dust (Table 6) when comparing mean and range for AOD. The comparison for AAOD is poor for the tuned and mineralogy simulations with CAM4; however CAM5-m matches observations reasonably well with a predicted range larger than observed (Table 6b). CAM4-t and CAM5-t are more accurate at capturing the mean observed SSA across many sites, while CAM4-m performs worse than CAM5-m (Fig. 9e, f). CAM4-m SSA is biased high and has decreased range of variability and less correlation than CAM4-t (Table 6). CAM5 overall is dustier with $8.2 \%$ of grid cells meeting $\mathrm{AOD}_{\text {dust }}>0.5 \cdot \mathrm{AOD}_{\text {total }}$, and $27.5 \%$ of these have column hematite percents greater than $1.5 \%$. In 
contrast, CAM4-m has $56 \%$ fewer "dusty" grid cells, with only $17.6 \%$ of these containing total column hematite percents above $1.5 \%$. While CAM5-t does well in matching AERONET SSA. CAM5-m predicts lower SSA and a greater range than observed (Fig. 9f).

Adding mineralogy to CAM4 does not seem to improve the simulation of AERONET AOD, AAOD and SSA, whereas it does marginally in CAM5. Adding mineralogy to CAM5 adds to the quality of the simulation at the AERONET sites because of the higher amounts of dust, as well as more hematite (Figs. 10 and 11). Black carbon is a more efficient absorber than hematite (SSA $=0.17$ vs. 0.6 , for black carbon and hematite, respectively). Black carbon is twice as abundant in CAM4-m as in CAM5-m in dust-dominated regions, and it dominates the SSA signal (Figs. 10 and 11). The lower black carbon concentrations may be due to the internal mixture assumption for BC in CAM5 (Wang et al., 2013). Recognize that, while the aerosol forcing data sets and meteorology were the same for both simulations, the simulations of CAM4 and CAM5 have many differences, including physical parameterizations for aerosol transport and deposition along with different radiation schemes. Overall, inclusion of mineralogy did not improve comparisons at AERONET stations for AOD, AAOD and SSA.

\subsection{Radiative forcing}

\subsubsection{Clear-sky radiative forcing}

The TOA radiative forcing efficiency (RFE, $\mathrm{Wm}^{-2} \tau^{-1}$ ) of dust is compared to clear-sky satellite-based observations over the North Atlantic (Li et al., 2004) and the Sahara (Zhang and Christopher, 2003; Patadia et al., 2009) for both simulations with tuned dust and mineralogy in CAM4 and CAM5 (Table 7). Out of the three shortwave observations considered, CAM4-t matches two of the observations better than CAM4-m. The clear-sky forcing efficiency observed by Li et al. (2004) during June, July and August (JJA) over the North Atlantic is captured by CAM4-t, while CAM4-m simulated a smaller forcing. The extinction coefficient of tuned dust is larger than that of individual minerals; the refractive indices of tuned dust were calculated based on Maxwell-Garnet internal mixture of non-absorbing clays and quartz and absorbing hematite. The real part (scattering) and the imaginary part (absorbing) of the refractive index at $533 \mathrm{~nm}$ are larger for tuned dust than for each of the minerals except for the real part in montmorillonite and for hematite (dust $(\lambda=533 \mathrm{~nm}): 1.515-i 0.00236$; illite $(\lambda=533 \mathrm{~nm}): 1.415-i 0.00103$; kaolinite $(\lambda=533 \mathrm{~nm})$ : $1.493-i 9.954 \times 10^{-5}$; montmorillonite $(\lambda=533 \mathrm{~nm}): 1.529$ $-i 0.00185$; hematite $(\lambda=533 \mathrm{~nm}): 2.967-i 0.7997$; restof-dust blend $(\lambda=533 \mathrm{~nm}): 1.51-i 0.00105)$. Hematite has much larger imaginary and real parts; however the density of hematite is twice as large as the densities for tuned dust and for each of the minerals. Since the mass extinction effi- ciency is a factor of $1 /$ density, hematite has a smaller mass extinction efficiency than all other minerals. The reason that CAM4-m has a smaller forcing efficiency is that, for similar dust and mineral loads, the amount of radiation scattered back to space is dominated by the greater extinction efficiency of tuned dust; e.g., tuned dust results in $13 \%$ more extinction per unit mass than mineralogy. For the "low" dust season - November, December and January (NDJ) - the same phenomena is found: with similar dust and mineral loads, tuned dust results in a more negative forcing efficiency at TOA for the CAM4-t case. However in this case, CAM4-m more closely matches the observation; however, the significance of this is not clear as clear-sky measurements during winter may be capturing black carbon from biomass burning as well as dust (Li et al., 2004).

CAM5-m underestimates the SW forcing efficiency observed by Li et al. (2004), while CAM5-t more closely matched this (Table 7). The reason for this is that mineralogy is significantly more absorbing with higher column concentration of hematite, despite similar loadings and optical depths (Fig. 16). Over the same domain but for the low dust season, the mineralogy simulation more closely matches the observation, most likely from the more absorbing mineralogy compared to the tuned dust. While both mineralogy simulations (CAM4-m and CAM5-m) fall within the range of the observation for the NDJ season, the dust loading differs between these, 0.38 and $0.26 \mathrm{Tg}$, respectively, with optical depths 0.054 and 0.046 . The extinction per mass is higher for CAM5-m; however since CAM5-m is also more absorbing than CAM4-m, the resulting RFEs are similar.

The clear-sky forcing efficiency over north Africa is approximately 0 in the observations for a surface albedo of 0.4 during "high" dust season (JJA) (Patadia et al., 2009). Both CAM4 and CAM5 simulations with tuned dust match the observations better than the simulations with mineralogy. Over north Africa, there are competing mechanisms for the TOA forcing efficiency in both reality and modeling. Tuned dust in CAM4 is more absorbing than CAM4-m; however it is also more efficient at scattering incoming SW radiation. In addition to scattering more incoming radiation (cooling at TOA), it will also absorb more SW radiation reflected from the surface (warming at TOA). CAM4-m is not as efficient at scattering incoming solar radiation and results in less cooling at the surface. Since TOA forcing is the sum of forcing at the surface and in the atmosphere, the smaller cooling from CAM4-m and similar atmospheric heating for both CAM4$\mathrm{t}$ and CAM4-m results in an increased positive forcing at TOA for CAM4-m. In CAM5, the simulation with mineralogy has relatively high concentrations of hematite in this region (Figs. 3d, 11a), and hence low SSA (Fig. 16d), and it absorbs both incoming solar radiation and reflected SW radiation; for similar loads and optical depths, CAM5-m simulates increased surface cooling and 4 times as much heating in the atmosphere, explaining the net positive SW forcing at TOA. 

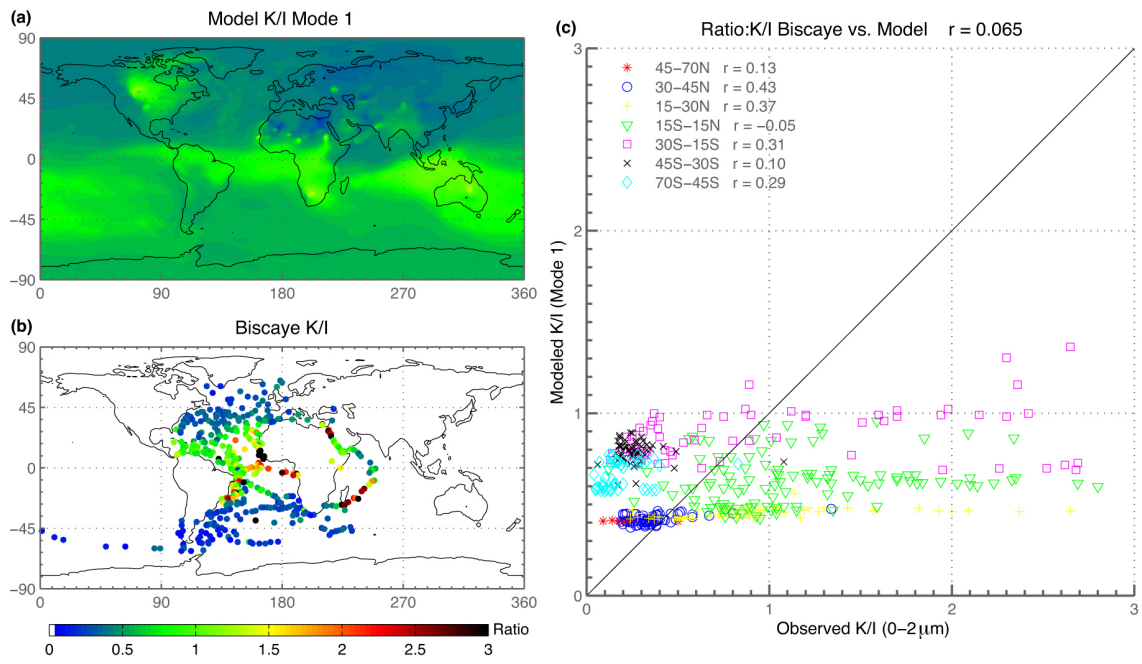

Figure 8. Kaolinite/illite mineral ratio of wet and dry deposition for mode 1 from CAM5 (a) ( $\mathrm{kg} \mathrm{K} / \mathrm{kg} \mathrm{I})$ and from characteristic basal X-ray diffraction maxima ratios of K / I of ocean core sediments (b) (Biscaye 1965). Data are segregated by latitude bands in scatterplot (c).

Table 7. Comparison of observed top-of-atmosphere clear-sky radiative forcing efficiencies (RFEs) (Wm ${ }^{-2} \tau^{-1}$ ) over the North Atlantic and north Africa regions with simulated RFE. Simulations are for CAM4 and CAM5 with release dust, tuned dust and mineralogy in the upper portion of the table. The sensitivity studies with tuned dust and release size distribution, and with the source of hematite coming solely from the soil clay fraction for CAM4 and CAM5, comprise the lower portion of the table.

\begin{tabular}{|c|c|c|c|c|}
\hline $\begin{array}{l}\text { Reference; } \\
\text { domain }\end{array}$ & $\begin{array}{l}\text { Li et al. (2004); } 15-25^{\circ} \mathrm{N}, \\
45-15^{\circ} \mathrm{W}\end{array}$ & $\begin{array}{l}\text { Li et al. (2004); } 15-25^{\circ} \mathrm{N} \text {, } \\
45-15^{\circ} \mathrm{W}\end{array}$ & $\begin{array}{l}\text { Zhang and Christopher (2004); } \\
15-35^{\circ} \mathrm{N}, 18^{\circ} \mathrm{W}-40^{\circ} \mathrm{E}\end{array}$ & $\begin{array}{l}\text { Patadia et al. (2009); } 15-30^{\circ} \mathrm{N} \text {, } \\
30^{\circ} \mathrm{E}-10^{\circ} \mathrm{W}\end{array}$ \\
\hline Observed & TOA : SW (JJA) $-\mathbf{3 5} \pm \mathbf{3}$ & TOA : SW (NDJ) $-\mathbf{2 6} \pm \mathbf{3}$ & TOA : LW (Sep) 15 & TOA : SW (JJA) 0 (albedo $=0.4)$ \\
\hline CAM4-d & -25.2 & -30.6 & 0.0 & 18.1 \\
\hline CAM4-t & -34.1 & -36.2 & 9.5 & 3.8 \\
\hline CAM4-m & -25.3 & -25.9 & 9.9 & 11.6 \\
\hline CAM5-d & -19.7 & -22.0 & 4.4 & 21.9 \\
\hline CAM5-t & -31.2 & -31.0 & 6.7 & -1.3 \\
\hline CAM5-m & -23.4 & -23.9 & 5.6 & 10.0 \\
\hline CAM4-trs & -32.4 & -33.3 & 7.4 & -1.5 \\
\hline CAM5-trs & -32.0 & -31.7 & 5.8 & -3.8 \\
\hline CAM4-mH & -25.4 & -25.9 & 9.9 & 11.4 \\
\hline CAM5-mH & -25.7 & -25.8 & 5.7 & 5.9 \\
\hline
\end{tabular}

Both CAM4 and CAM5 underestimate the clear-sky LW forcing efficiency observed by Zhang and Christopher (2004) over north Africa in September. The difference between CAM4-m and CAM4-t is not meaningful since the same LW optical properties were prescribed for both tuned dust and mineralogy. CAM5-m does worse than CAM5-t for this observation. For CAM5-m, the clay minerals and hematite were the only minerals included, and the silt-sized minerals such as quartz and calcite were not explicitly modeled. Quartz dominates absorption in the IR spectrum with additional significant contributions from both the silt-sized and clay minerals (Sokolik and Toon, 1999). CAM5-m is not capturing the quartz signal or the other silt-sized mineral signals, and thus it simulates less surface heating and a smaller LW TOA forcing. The simulations of dust and mineralogy in CAM4 and CAM5 only account for absorption in the LW and ex- clude scattering, which has been shown to underestimate the $\mathrm{LW}$ forcing by up to $50 \%$ at TOA and $15 \%$ at the surface (Dufresne et al., 2002) and serves to explain why both models underestimate the observed forcing.

\subsubsection{All-sky radiative forcing}

All-sky radiative forcing is a delicate balance between heating and cooling of SW and LW radiation (Table 8, Figs. 1214). The differen.ce between tuned dust and mineralogy for the all-sky TOA radiative forcing spatial distribution for CAM4 (Fig. 14a, c) indicates intensified heating over desert and less cooling everywhere else. This is consistent with the more absorbing nature of tuned dust whose optical properties represent an internal mixture of minerals compared with mineralogy with combined optics of the external mixing of illite, kaolinite, montmorillonite, feldspar and hematite, along with 
Table 8a. Simulated annual average global all-sky radiative forcing.

\begin{tabular}{lrrrlllllll}
\hline Model & AOD & TOA & TOAsw & TOAlw & ATM & ATMsw & ATMlw & SFC & SFCsw & SFClw \\
\hline CAM4-d & 0.029 & 0.08 & 0.08 & 0 & 1.59 & 1.59 & 0 & -1.51 & -1.51 & 0 \\
CAM4-t & 0.015 & -0.05 & -0.14 & 0.09 & 0.23 & 0.56 & -0.33 & -0.28 & -0.7 & 0.42 \\
CAM4-m & 0.015 & 0.05 & -0.04 & 0.09 & 0.23 & 0.56 & -0.33 & -0.18 & -0.6 & 0.42 \\
CAM5-d & 0.023 & 0.17 & 0.09 & 0.08 & 0.96 & 1.33 & -0.37 & -0.8 & -1.25 & 0.45 \\
CAM5-t & 0.033 & -0.17 & -0.33 & 0.16 & 0.22 & 0.77 & -0.55 & -0.39 & -1.1 & 0.71 \\
CAM5-m & 0.031 & 0.05 & -0.08 & 0.13 & 0.67 & 1.17 & -0.5 & -0.62 & -1.25 & 0.63 \\
CAM4-trs & 0.021 & -0.15 & -0.24 & 0.09 & 0.24 & 0.57 & -0.33 & -0.38 & -0.8 & 0.42 \\
CAM4-mH & 0.015 & 0.05 & -0.04 & 0.09 & 0.23 & 0.56 & -0.33 & -0.18 & -0.6 & 0.42 \\
CAM5-trs & 0.042 & -0.29 & -0.47 & 0.17 & 0.25 & 0.83 & -0.57 & -0.55 & -1.29 & 0.75 \\
CAM5-mH & 0.032 & -0.04 & -0.15 & 0.12 & 0.58 & 1.07 & -0.48 & -0.62 & -1.22 & 0.60 \\
\hline
\end{tabular}

Table 8b. Simulated regional annual average global all-sky radiative forcing.

\begin{tabular}{|c|c|c|c|c|c|c|c|c|c|c|c|}
\hline & Model & TOA & TOAsw & TOAlw & ATM & ATMsw & ATMlw & SFC & SFCsw & SFClw & AOD \\
\hline \multirow{4}{*}{$\begin{array}{l}\text { North Atlantic; } 0-30^{\circ} \mathrm{N} \text {, } \\
50-20^{\circ} \mathrm{W}\end{array}$} & CAM4-t & -0.39 & -0.54 & 0.15 & 1.24 & 1.60 & -0.36 & -1.62 & -2.14 & 0.51 & 0.05 \\
\hline & CAM4-m & -0.13 & -0.28 & 0.16 & 1.14 & 1.50 & -0.36 & -1.27 & -1.78 & 0.52 & 0.05 \\
\hline & CAM5-t & -0.39 & -0.56 & 0.16 & 0.76 & 1.07 & -0.30 & -1.16 & -1.63 & 0.47 & 0.04 \\
\hline & CAM5-m & 0.09 & -0.04 & 0.13 & 1.57 & 1.83 & -0.26 & -1.48 & -1.86 & 0.38 & 0.04 \\
\hline \multicolumn{12}{|l|}{ North Africa; $5-35^{\circ} \mathrm{N}$, } \\
\hline \multirow[t]{4}{*}{$18^{\circ} \mathrm{W}-40^{\circ} \mathrm{E}$} & CAM4-t & -0.12 & -1.38 & 1.26 & 2.14 & 8.10 & -5.96 & -2.26 & -9.48 & 7.22 & 0.21 \\
\hline & CAM4-m & 1.30 & 0.02 & 1.29 & 2.28 & 8.28 & -6.00 & -0.98 & -8.26 & 7.28 & 0.20 \\
\hline & CAM5-t & -1.10 & -2.90 & 1.81 & 1.61 & 9.82 & -8.21 & -2.71 & -12.73 & 10.02 & 0.36 \\
\hline & CAM5m & 1.48 & 0.02 & 1.46 & 7.15 & 14.57 & -7.42 & -5.68 & -14.56 & 8.88 & 0.34 \\
\hline \multicolumn{12}{|l|}{ W. Indian Ocean; } \\
\hline \multirow[t]{4}{*}{$10^{\circ} \mathrm{S}-15^{\circ} \mathrm{N}, 50-70^{\circ} \mathrm{E}$} & CAM4-t & -0.88 & -1.42 & 0.54 & 1.35 & 3.27 & -1.92 & -2.23 & -4.69 & 2.47 & 0.10 \\
\hline & CAM4-m & -0.21 & -0.76 & 0.55 & 1.31 & 3.25 & -1.93 & -1.52 & -4.00 & 2.49 & 0.09 \\
\hline & CAM5-t & -1.65 & -2.45 & 0.79 & 1.27 & 4.09 & -2.82 & -2.93 & -6.54 & 3.61 & 0.18 \\
\hline & CAM5-m & -0.48 & -1.12 & 0.64 & 3.83 & 6.38 & -2.54 & -4.31 & -7.50 & 3.18 & 0.17 \\
\hline
\end{tabular}

an internal mixture of calcite, montmorillonite, quartz and illite; the result for CAM4-t being increased surface cooling with nearly identical atmospheric forcings and an overall, albeit small, net cooling compared to the small overall net warming from CAM4-m. On the other hand, the spatial pattern for CAM5-m indicates an intensification of heating over source regions, largely due to the $\mathrm{SW}$ atmospheric heating from hematite's absorption of both incoming and reflected SW radiation (Figs. 14d, 3d, Table 8b). Over bright reflective surfaces such as desert, higher column concentrations of hematite in CAM5-m absorb incoming solar radiation as well as SW radiation reflected by the high-albedo surface resulting in less solar radiation being reflected back out at TOA. While the larger absorption of incoming solar radiation of CAM5-m does not change the SW forcing at TOA, the absorption of reflected SWs does affect this, and over desert it is clear that both these processes result in a positive atmospheric forcing twice as large as the cooling at the surface (Table 8b). Net surface forcing for CAM4-t, CAM4-m and CAM5-t have similar spatial patterns as TOA forcing, however, CAM5-m indicates much greater surface cooling every- where (Fig. 12). The spatial pattern of net atmospheric forcing for CAM4-t and CAM4-m are nearly identical (Fig. 13a, c), arising from the very similar SSA maps (Fig. 16a, c); for CAM5-m, the atmospheric heating due to both absorption of incoming and reflected SWs is clearly seen compared to CAM5-t (Fig. 13b, d). In the three major regions contributing to RF from dust - the North Atlantic, north Africa and western Indian Ocean (Yoshioka et al., 2007) - the changes between mineralogy and tuned dust are dominated by SW forcing (Table 8b).

To summarize, there are two different mechanisms for increased positive TOA forcing for both models with mineralogy. For CAM4, while the SSA is higher for the case with explicit mineralogy, the overall extinction efficiency is higher for tuned dust, largely due to the fact that the optical properties for tuned dust are simulated as an internal mixture of illite, kaolinite, calcite, quartz and hematite. For CAM5, both dust and mineralogy are internally mixed with other aerosol species; however the SSA for mineralogy is much lower due to the high concentrations of hematite over key regions contributing to the global RF from dust. While it is not clear that 
Table 9. Percent change in annual all-sky radiative forcing for CAM4 and CAM5 from default to tuned dust (C4:d-t, C5 : d-t), tuned dust to tuned dust plus release size distribution (C4:t-trs, C5:t-trs) and tuned dust to mineralogy (C4:t-m, C5: t-m).

\begin{tabular}{|c|c|c|c|c|c|c|c|c|c|}
\hline$\%$ change & TOA & TOAsw & TOAlw & ATM & ATMsw & ATMlw & SFC & SFCsw & SFClw \\
\hline $\mathrm{C} 4$ : d-t & $-162.5 \%$ & $-275.0 \%$ & N/A & $-85.5 \%$ & $-64.8 \%$ & N/A & $-81.5 \%$ & $-53.6 \%$ & N/A \\
\hline $\mathrm{C} 4: \mathrm{t}$-trs & $200.0 \%$ & $71.4 \%$ & $0.0 \%$ & $4.3 \%$ & $1.8 \%$ & $0.0 \%$ & $35.7 \%$ & $14.3 \%$ & $0.0 \%$ \\
\hline $\mathrm{C} 4: \mathrm{t}-\mathrm{m}$ & $-200.0 \%$ & $-71.4 \%$ & $0.0 \%$ & $0.0 \%$ & $0.0 \%$ & $0.0 \%$ & $-35.7 \%$ & $-14.3 \%$ & $0.0 \%$ \\
\hline C5:d-t & $-200.0 \%$ & $-466.7 \%$ & $100.0 \%$ & $-77.1 \%$ & $-42.1 \%$ & $48.6 \%$ & $-51.3 \%$ & $-12.0 \%$ & $57.8 \%$ \\
\hline C5:t-trs & $70.6 \%$ & $42.4 \%$ & $6.3 \%$ & $13.6 \%$ & $7.8 \%$ & $3.6 \%$ & $41.0 \%$ & $17.3 \%$ & $5.6 \%$ \\
\hline C5:t-m & $-129.4 \%$ & $-75.8 \%$ & $-18.8 \%$ & $204.5 \%$ & $51.9 \%$ & $-9.1 \%$ & $59.0 \%$ & $13.6 \%$ & $-11.3 \%$ \\
\hline
\end{tabular}
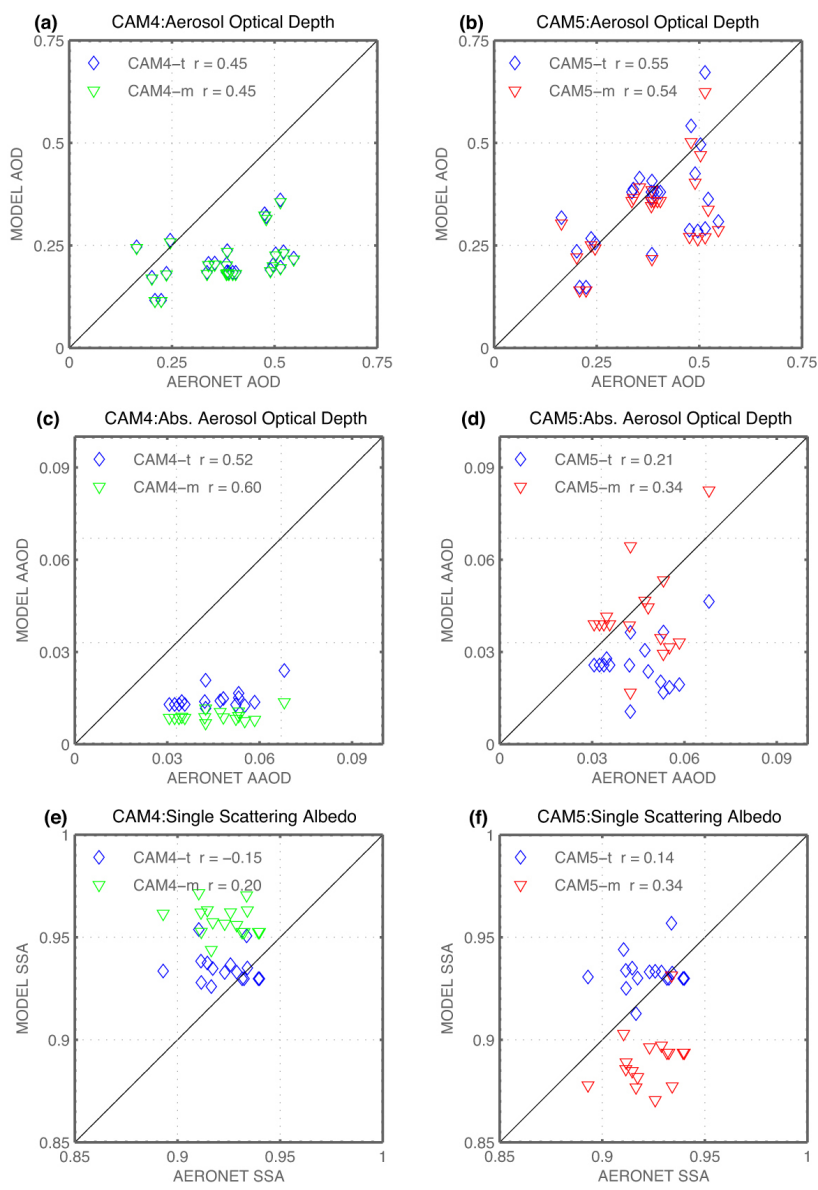

Figure 9. Annually averaged modeled aerosol optical depth (a, b), absorbing aerosol optical depth (c, d) and single scattering albedo (e, f) at $533 \mathrm{~nm}$ compared to annually averaged AERONET retrievals at sites where modeled $\mathrm{AOD}_{\text {dust }}>\mathrm{AOD}_{\text {total }} \times 0.5$. CAM4 (a, c, e) and CAM5 (b, d, f) are shown.

mineralogy improves global dust RF, and in several observations it appears to do worse, all four simulations fall within the range of previous RF modeling estimates (Yoshioka et al., 2007; Woodward, 2001; Miller et al., 2004, 2006).

A comparison to radiative forcing efficiency from another study that included mineralogy (Balkanski et al., 2007) is not straightforward since that study inferred that the ideal
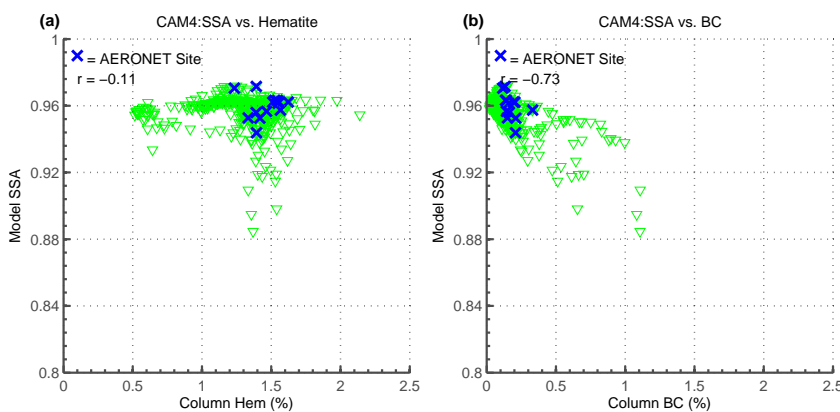

Figure 10. Model single scattering albedo at grid cells with $\mathrm{AOD}_{\text {dust }}>0.5 \cdot \mathrm{AOD}_{\text {total }}$ in CAM4 mineralogy is compared to total percent column hematite (a) and total percent column black carbon (b). The locations of AERONET sites used in the comparison in Fig. 9 are plotted in blue.
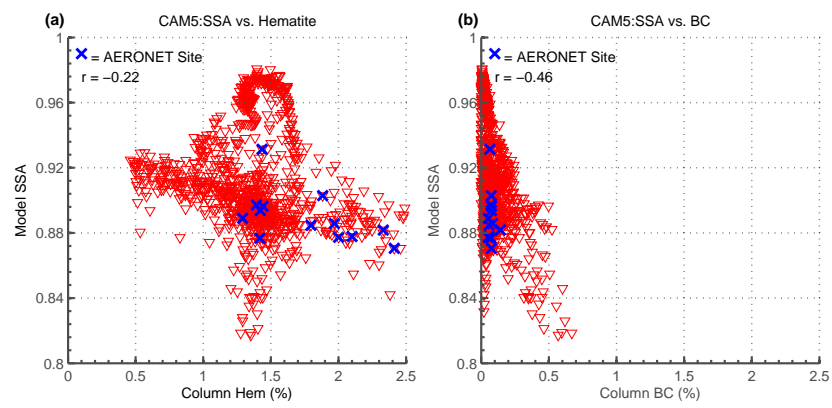

Figure 11. Model single scattering albedo from CAM5 with mineralogy is compared to total percent column hematite (a) and total percent column black carbon (b). The locations of AERONET sites used in the comparison in Fig. 9 are plotted in blue.

hematite inclusion for an internal dust mixture is twice the value in this study. For both CAM4 and CAM5 simulations with mineralogy, the hematite content in the soil distributions is $1.4 \%$ by mass, or $0.7 \%$ by volume, while the tuned dust assumes $0.8 \%$ hematite by mass, or $0.4 \%$ by volume. For the case with $1.5 \%$ hematite by volume, they report TOA forcing efficiency which is too cooling compared to the clear-sky RFE reported by Li et al. (2004), while the simulated surface RFE matched observations. From this, the atmospheric heating efficiency was underestimated. The re- 

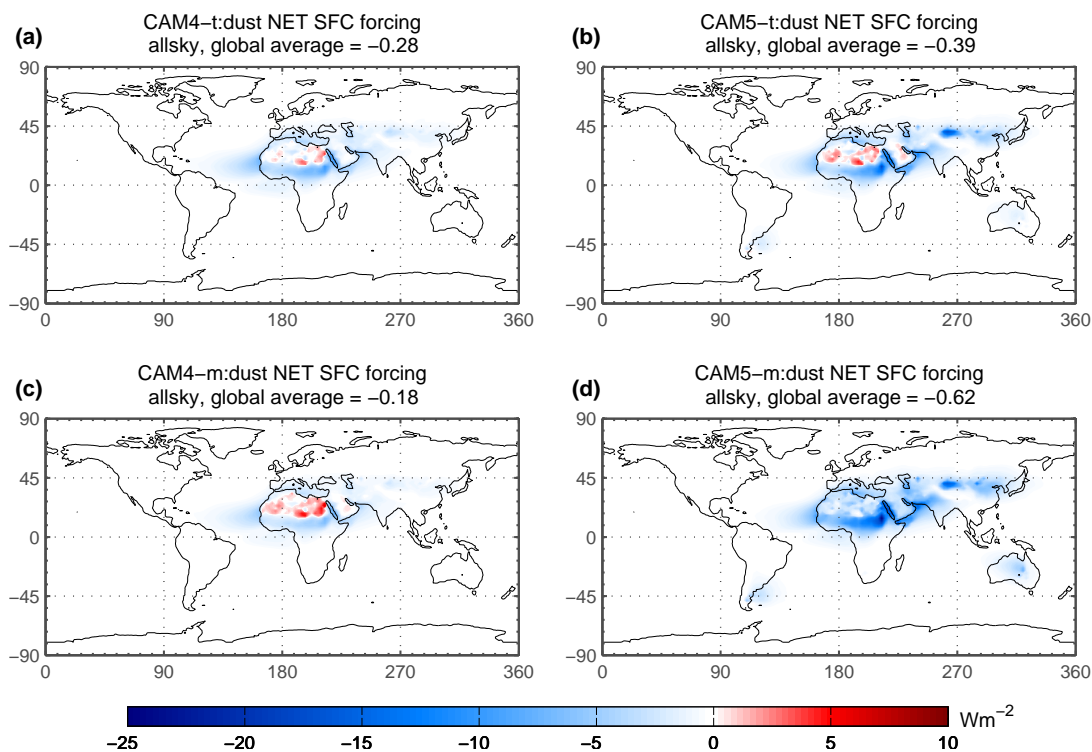

Figure 12. Spatial distribution of annual all-sky radiative forcing $(\mathrm{SW}+\mathrm{LW})$ at the surface for CAM4 with tuned dust and with mineralogy $(\mathbf{a}, \mathbf{c})$ and for CAM5 with tuned dust and mineralogy $(\mathbf{b}, \mathbf{d})$.
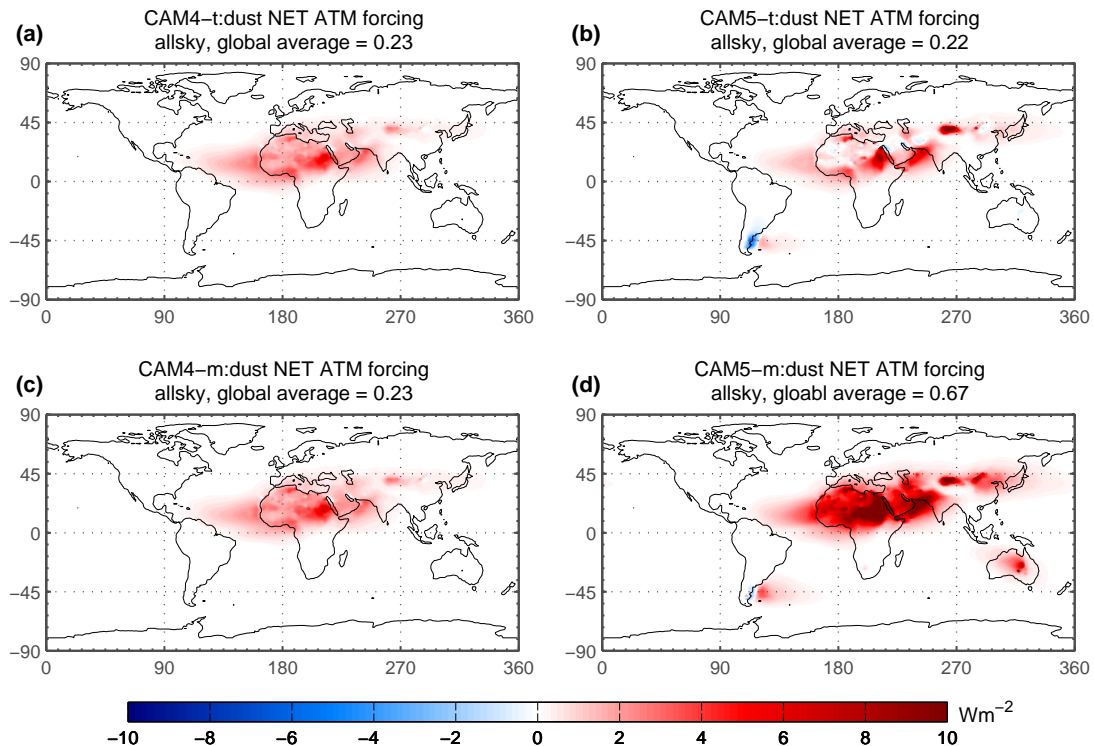

Figure 13. Spatial distribution of annual all-sky radiative forcing $(\mathrm{SW}+\mathrm{LW})$ in the atmosphere for CAM4 with tuned dust and with mineralogy (a, c) and for CAM5 with tuned dust and mineralogy (b, d).

sults for clear-sky TOA forcing efficiency are less cooling in both CAM4-m and CAM5-m; however the surface RFE in both cases is very similar to the observed $-65 \pm 3,-63$ and $-64 \mathrm{Wm}^{-2} \tau^{-1}$. Additionally, both cases with mineralogy come close to the estimated atmosphere heating efficiency of $30 \pm 4 \mathrm{Wm}^{-2} \tau^{-1}$, with values of 38 and $41 \mathrm{Wm}^{-2} \tau^{-1}$ for CAM4-m and CAM5-m, respectively.

\subsection{Sensitivity to size}

Changing the assumed optical properties derived from optimized refractive indices is most important in determining all-sky DRF (CAM4-t, CAM5-t), with size (CAM4trs) and mineralogy (CAM4-m) following with comparable importance in CAM4 and with mineralogy (CAM5$\mathrm{m})$ and then size in CAM5 (CAM5-trs) (Table 9). Comparing to clear-sky RFE observations, the order of importance is less clear for CAM4, with tuned optics, scaveng- 

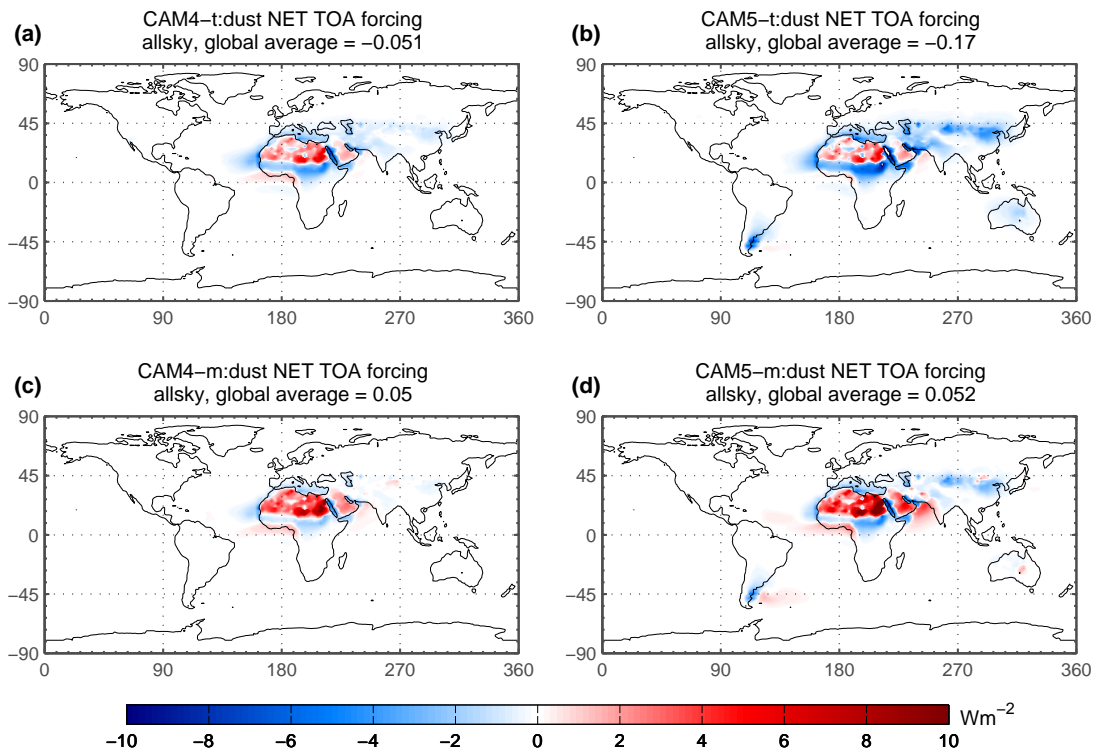

Figure 14. Spatial distribution of annual all-sky radiative forcing (SW + LW) at the top of atmosphere for CAM4 with tuned dust and with mineralogy (a, c) and for CAM5 with tuned dust and mineralogy (b, d).

ing and release size distribution (CAM4-trs) doing worse $\left(-32.0 \mathrm{Wm}^{-2} \tau^{-1}\right)$ than CAM4-t $\left(-33.9 \mathrm{Wm}^{-2} \tau^{-1}\right)$ over North Atlantic JJA and better $\left(-32.7 \mathrm{Wm}^{-2} \tau^{-1}\right)$ during NDJ than CAM4-t $\left(-35.9 \mathrm{Wm}^{-2} \tau^{-1}\right)$ (Table 7). Comparing to observations from Patadia et al. (2009), both CAM4 and CAM5 with tuned dust plus release size distribution (CAM4-trs and CAM5-trs) overcompensates the cooling efficiency, while both simulations with mineralogy (CAM4$\mathrm{m}$ and CAM5-m) predict heating (Table 7). In general, the higher concentrations of small particles in the simulations using release sizes result in increased reflectivity and increased cooling at TOA. For clear-sky observations, it appears that size is more important than mineralogy, and of comparable importance to optics.

Comparing to AERONET retrievals, root mean square errors (RMSEs) are calculated for the tuned dust plus release size distribution simulations (CAM4-trs and CAM5trs) compared to the RMSE for the tuned and mineralogy cases for AOD, AAOD and SSA. For CAM4, RMSEs in AOD for the tuned (CAM4-t) and mineralogy (CAM4-m) simulations are similar and higher than for the tuned plus release size case (CAM4-trs) (0.197, 0.152 and 0.200 for CAM4-t, CAM4-trs and CAM4-m, respectively). For AAOD and SSA, however, RMSE for mineralogy is the highest followed by identical errors for the tuned and tuned release size simulations, and by tuned plus release size then tuned for AAOD (0.032, 0.032 and 0.038 for CAM4-t, CAM4-trs and CAM4-m, respectively) and SSA (0.020, 0.029 and 0.039 for CAM4-t, CAM4-trs and CAM4m, respectively). This indicates that, when comparing to AOD for CAM4, the release particle size distribution provides the best match to observations with mineralogy and tuned dust approximately equal in ability. However for AAOD and SSA, mineralogy has the poorest match to observations, while either the tuned cases with optimized size distribution and with release size distribution are equal in ability (AAOD) or the release size distribution performs worse (SSA). For CAM5, RMSE for AOD is lower for each case than CAM4. The CAM5 simulation with tuned dust better matches observations followed by mineralogy and then tuned plus release size distribution $(0.112$, 0.124 and 0.118 for CAM5-t, CAM5-trs and CAM5-m, respectively). Similarly, for AAOD, the RMSEs for the CAM5 simulations are all lower than for CAM4. Again, the CAM5 simulation with mineralogy best matches observations followed by tuned plus release dust and then tuned $(0.023,0.022$ and 0.015 for CAM5-t, CAM5-trs and CAM5-m, respectively). And for RMSE for SSA, the simulation with mineralogy most poorly matches observations, while the simulation with tuned dust best matches $(0.017,0.023$ and 0.036 for CAM5-t, CAM5-trs and CAM5-m, respectively). Thus CAM5 better captures the variability in AERONET than CAM4; however, the simulations with tuned dust and release size distribution help the comparison for CAM4 and hinder it for CAM5. With the exception of AAOD in CAM5, the tuned runs overall are most accurate, with mineralogy and tuned plus release size distribution following, depending on the measurement in question (Fig. 15). Despite this, the size distribution of dust estimated from AERONET more closely matches the size distribution derived from Kok (2011) (Albani et al., 2014). Overall, including mineralogy is comparable to changes in size and optics when comparing to AERONET; however, when comparing to radiative forcing, it is less clear whether including mineralogy is as important as optics or size changes. 

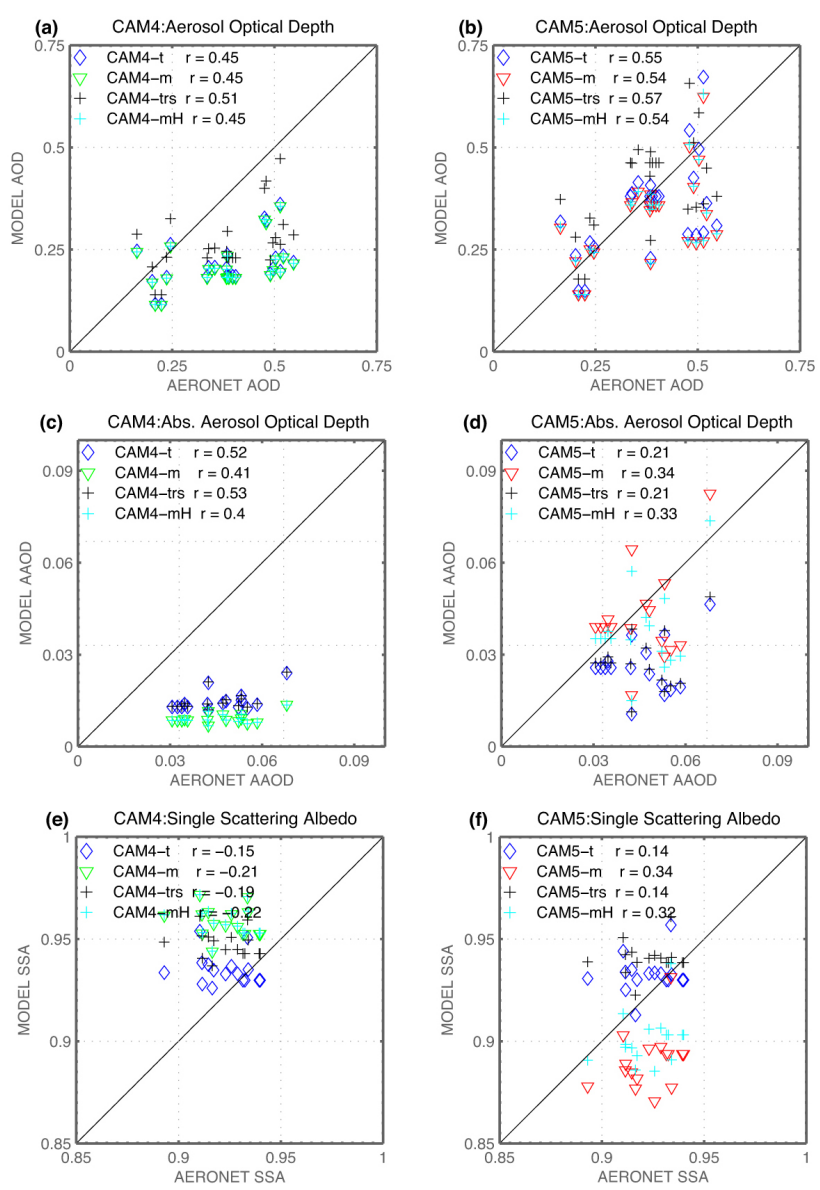

Figure 15. Annually averaged modeled aerosol optical depth (a, b), absorbing aerosol optical depth (c, d) and single scattering albedo (e,f) compared to annually averaged AERONET retrievals at $533 \mathrm{~nm}$ at sites where modeled $\mathrm{AOD}_{\text {dust }}>\mathrm{AOD}_{\text {total }} \cdot 0.5$. CAM4 (a, c, e) and CAM5 (b, d, f) are shown for tuned dust, mineralogy, tuned dust + release size and mineralogy with hematite in soil clay only.

\subsection{Sensitivity to soil distribution of hematite}

Testing whether or not including hematite only for the soil clay and not for soil silt made no difference for CAM4; hematite concentrations were already low enough, particularly over dust source regions (Fig. 2f) where removing the hematite from the silt-sized soils did not have an impact on DRF, RFE observations or comparisons to AERONET retrievals (Tables 6a, b, 7, 8a, Fig. 15, Supplement Fig. S2a, c).

On the other hand, this sensitivity test was more interesting for CAM5. Comparing to AERONET retrievals of AAOD and SSA (Table 6a, b), excluding hematite from the coarse soil fraction (CAM5-mH) does better than including it (CAM5-m). While the mean AAOD for the case without coarse hematite (CAM5-mH) differs more than including it (CAM5-m), the variability is closer to the observed variability. And for SSA, the mean SSA for the case without coarse hematite (CAM5-mH) is closer than CAM5-m to the mean in AERONET, with the variability coming even closer to the observed variability. When comparing to the observations of clear-sky RFE, in all cases except for the LW observation, the case without coarse hematite (CAM5-mH) does better than the case with both fine and coarse hematite (CAM5-m) in matching these observations (Table 7). Finally, when examining the all-sky DRF, while the surface forcings for the case with both fine and coarse hematite (CAM5-m) and without coarse hematite (CAM5-mH) are very similar, the reduction of atmospheric heating for CAM5-mH is tempered by the smaller overall hematite concentration, particularly close to source regions where there are fewer large hematite particles able to absorb radiation. And therefore, at TOA, the sign changes from slightly positive for CAM5-m, $+0.05 \mathrm{Wm}^{-2}$, to slightly negative for CAM5-mH, $-0.04 \mathrm{Wm}^{-2}$ (Table $8 \mathrm{a}$ ). The spatial patterns for the mineralogy simulations with and without coarse hematite (CAM5-m and CAM5-mH, respectively) are similar and indicate an intensification of heating over source regions, largely due to the $\mathrm{SW}$ atmospheric heating from hematite's absorption of both incoming and reflected SW radiation (Supplement Fig. S2d, Figs. 13d, 3d, Table 8a). The positive atmospheric forcing for CAM5 with hematite in both the fine and coarse modes (CAM5-m) is 3 times as large as for the simulation with tuned dust (CAM5$\mathrm{t}$ ), it is a little over twice as large for the mineralogy case without coarse hematite (CAM5-mH), with the balance between the lesser atmospheric forcing combined with the similar surface cooling being sufficient to change the sign at TOA for CAM5-mH (Table 8a). Our results suggest that excluding the coarse mode hematite is more realistic, which is similar to the methodology proposed in a new mineralogy map (Journet et al., 2014).

\subsection{Quantifying uncertainty}

As this study is the first we are aware of to simulate the radiative forcing by modeling the distribution of individual minerals in place of dust, it is not possible to compare the uncertainties in our model with those from another study. In an attempt to quantify the uncertainties associated with the mineralogy simulations, we identify the sources of error to estimate an upper bound uncertainty. From the mineral source maps derived from Claquin et al. (1999), the standard deviation in soil mineral content comprises up to $33 \%$ of the given mineral contents. Uncertainties from direct radiative forcing of dust based on simulations included in the Intergovernmental Panel on Climate Change (IPCC) have been previously estimated to be around $20 \%$ (Mahowald et al., 2010), which results from a combination of the uncertainty associated with dust distribution and the radiative forcing calculation itself. We do not have enough data to estimate the uncertainties in the mineral optical properties, although it is clear that the refractive indices for a given mineral can vary due to imperfections or inclusions which may reflect the geo- 
(a)

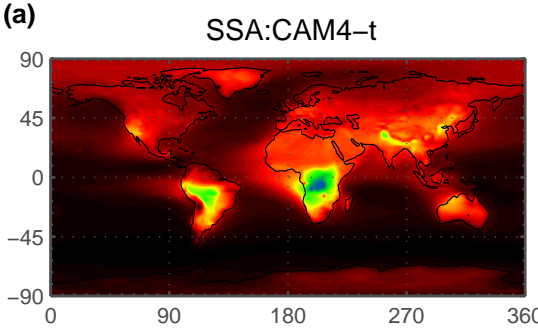

(b)

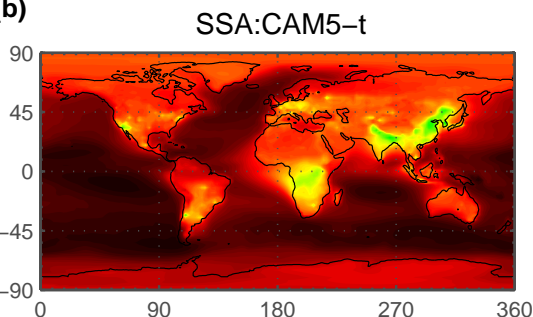

(c)

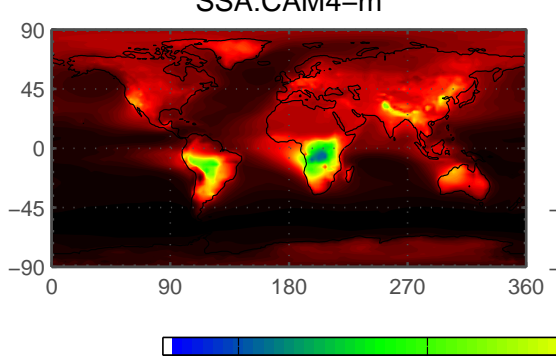

0.8 (d)

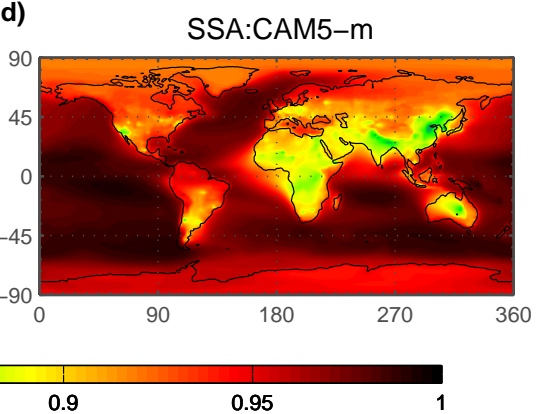

Figure 16. Model single scattering albedo for CAM4 with tuned dust (a), CAM5 with tuned dust (b), CAM4 with mineralogy (c) and CAM5 with mineralogy $(\mathbf{d})$.

graphic location of minerals. For example, chemical composition can vary between two samples collected at a single location, and have different refractive indices (Egan and Hilgeman, 1979). Additionally, two samples of the same mineral from different geographic locations can also have different refractive indices (Egan and Hilgeman, 1979). Therefore, we are only able to make a rough estimate of the uncertainty in the direct radiative forcing from mineralogy, which could be greater than $50 \%$. The ability to reduce the uncertainty is limited by available mineralogy maps, and having the mineralogy at every location is currently not feasible even with remote sensing. Daily averaged values for mineralogical data show large temporal variability in mineral ratios (Figs. 5 and 6), but spatial variability due to sub-grid-scale mineralogical heterogeneity could be as large or larger, and it is not assessed here. Effectively evaluating the mineralogy temporal and spatial variability could be achieved but only with many more current observations of mineralogy, and in particular observations of mineralogy as a function of particle size distribution.

\section{Discussion and conclusion}

For the first time, the ability to carry multiple types of minerals instead of only a bulk dust has been included in both CAM4 and CAM5, and mineralogy is coupled to radiation to simulate the impacts on radiative forcing. In general, the mineral distributions simulated in CAM4 and CAM5 lack the range of variability that the few available observations indicate, although this is improved when daily averaged values are compared instead of monthly means. Myriad reasons are responsible, including the averaged mineral source maps used in the simulations, the very limited number of mineralogy observations and the fact that atmospheric processing of minerals is not yet included in these models. In order to compare mineralogy collected over the course of a dust event to daily averaged model output, more current observations are needed with specification of the particle size distribution of the collected minerals. Despite the lack of observations to compare to, new mineral source maps such as from Journet et al. (2014) are needed along with chemical and physical atmospheric processing mechanisms to better compare to observations. An additional difficulty arises from soil properties and mineralogy that change on very short spatial scales in the real world, while the model assumes averages over large regions. Increasing the model resolution for the simulations is expensive but may be warranted, albeit only once we have improved source maps, included atmospheric mineral processing and have larger observational data sets to compare to.

In order to best match aerosol optical depth, absorbing aerosol optical depth and single scattering albedo from AERONET, it is not clear that adding mineralogy improves the comparison (Fig. 9). Sensitivity studies with size suggest that assumed size distributions are as important as the inclusion of mineralogy for correctly simulating the AERONET observations (Fig. 15). Similarly inclusion of mineralogy also did not significantly improve the simulation of forcing efficiency compared to observations, although the CAM5 mineralogy simulation with hematite arising from the soil clay fraction did somewhat improve this comparison. 
Changes in the assumed size distribution were similarly important in forcing efficiency calculations.

For calculating globally averaged radiative forcing, the simulations with mineral speciation are as important as the assumed size distribution. The single scattering albedo of dust is likely to be close to the threshold, where the sign of radiative forcing and climate response changes with small changes in SSA (Perlwitz et al., 2001). In both the CAM4 and CAM5 simulations, including mineralogy caused the modeled radiative forcing to switch from a small negative value $\left(-0.05\right.$ and $-0.17 \mathrm{Wm}^{-2}$ for CAM4 and CAM5 with tuned dust) to a small positive value $\left(+0.05 \mathrm{Wm}^{-2}\right.$ for both CAM4 and CAM5 with mineralogy). Notice that our results are sensitive to the poorly constrained simulation of mineralogy; improvements in the simulation of mineralogy could change the importance of mineralogy to aerosol properties and forcing.

A recent study of the radiative forcing of dust as a function of mineralogical composition that does not include the spatially explicit variability of minerals estimates a TOA forcing between -0.03 and $-0.25 \mathrm{Wm}^{-2}$ from mineral dust with an internal mixture of $1.5 \%$ hematite by volume (Balkanski et al., 2007). Both CAM4 and CAM5 cases with tuned dust ( $0.4 \%$ inclusion if hematite by volume) fall within the reported range.

In conclusion, more work is needed to improve input mineral source maps as well as mechanisms to simulate atmospheric processing. While mineralogy was not the most important factor impacting the simulation of direct radiative forcing in these simulations, it was responsible for increasing the radiative forcing for both models by about $0.1 \mathrm{Wm}^{-2}$. Mineralogy is likely to be more important for soluble iron impacts on biogeochemistry (Journet et al., 2008), as well as for aerosol-cloud interactions (Yin et al., 2002; Koehler et al., 2009; Hoose et al., 2008), and with this paper we have constructed the speciation framework to investigate mineralogy effects on these processes.

\section{The Supplement related to this article is available online at doi:10.5194/acp-15-537-2015-supplement.}

Acknowledgements. We thank Ives Balkanski for his comments and insight which improved the quality of the manuscript. Also, we thank the AERONET program for establishing and maintaining the used sites. These simulations were conducted at the National Center for Atmospheric Research, a National Science Foundation facility. N. Mahowald, R. Scanza and S. Albani would like to acknowledge the support of DOE DE-SC00006735, NSF 0932946 and NSF 1003509.

S. Ghan and X. Liu were funded by the US Department of Energy Atmospheric Systems Research and Climate Modeling programs. The Pacific Northwest National Laboratory (PNNL) is a multiprogram laboratory operated for DOE by Battelle Memorial Institute under contract DE-AC05-76RL01830.
Edited by: P. Formenti

\section{References}

Albani, S., Mahowald, N., Perry, A., Scanza, R., Zender, C., Heavens, N., Maggi, V., Kok, J., and Otto-Bliesner, B.: Improved dust representation in the Community Atmosphere Model, J. Adv. Model. Earth Syst., doi:10.1002/2013MS000279, 2014.

Bagnold, R. A.: The physics of wind blown sand and desert dunes, Methuen, London, 265, 1941.

Balkanski, Y., Schulz, M., Claquin, T., and Guibert, S.: Reevaluation of Mineral aerosol radiative forcings suggests a better agreement with satellite and AERONET data, Atmos. Chem. Phys., 7, 81-95, doi:10.5194/acp-7-81-2007, 2007.

Batjes, N.: A world dataset of derived soil properties by FAOUNESCO soil unit for global modelling, Soil Use Manage., 13, 9-16, 1997.

Biscaye, P. E.: Mineralogy and sedimentation of recent deep-sea clay in the Atlantic Ocean and adjacent seas and oceans, Geol. Soc. Am. Bull., 76, 803-832, 1965.

Caquineau, S., Gaudichet, A., Gomes, L., Magonthier, M. C., and Chatenet, B.: Saharan dust: Clay ratio as a relevant tracer to assess the origin of soil-derived aerosols, Geophys. Res. Lett., 25, 983-986, 1998.

Claquin, T., Schulz, M., and Balkanski, Y.: Modeling the mineralogy of atmospheric dust sources, J. Geophys. Res., 104, 22243222256, 1999.

Coakley Jr, J. A., Cess, R. D., and Yurevich, F. B.: The effect of tropospheric aerosols on the earth's radiation budget: A parameterization for climate models, Journal of Atmospheric Sciences, 40, 116-138, 1983.

Conley, A. J., Lamarque, J.-F., Vitt, F., Collins, W. D., and Kiehl, J.: PORT, a CESM tool for the diagnosis of radiative forcing, Geosci. Model Dev., 6, 469-476, doi:10.5194/gmd-6-469-2013, 2013.

Cwiertny, D. M., Baltrusaitis, J., Hunter, G. J., Laskin, A., Scherer, M. M., and Grassian, V. H.: Characterization and acid-mobilization study of iron-containing mineral dust source materials, J. Geophys. Res. Atmos., 113, D05202, doi:10.1029/2007JD009332, 2008.

DeMott, P. J., Sassen, K., Poellot, M. R., Baumgardner, D., Rogers, D. C., Brooks, S. D., Prenni, A. J., and Kreidenweis, S. M.: African dust aerosols as atmospheric ice nuclei, Geophys. Res. Lett., 30, 1732, doi:10.1029/2003GL017410, 2003.

Dubovik, O. and King, M. D.: A flexible inversion algorithm for retrieval of aerosol optical properties from Sun and sky radiance measurements, J. Geophys. Res. Atmos. (1984-2012), 105, 20673-20696, 2000.

Dubovik, O., Smirnov, A., Holben, B. N., King, M. D., Kaufman, Y. J., Eck, T. F., and Slutsker, I.: Accuracy assessments of aerosol optical properties retrieved from Aerososl Robotic Network (AERONET) Sun and sky radiance measurments, J. Geophys. Res., 105, 9791-9806, 2000.

Dufresne, J.-L., Gauier, C., Ricchiazzi, P., and Rouquart, Y.: Longwave Scattering Effects of Mineral Aerosols, Am. Meteorl. Soc., 59, 1959-1966, 2002.

Fecan, F., Marticorena, B., and Bergametti, G.: Parameterization of the increase of the aeolian erosion threshold wind friction ve- 
locity due to soil moisture for arid and semi-arid areas, Annales Geophys.-Atmos. Hydro. Space Sci., 17, 149-157, 1999.

Ghan, S. J. and Zaveri, R. A.: Parameterization of optical properties for hydrated internally mixed aerosol, J. Geophys. Res. Atmos., 112, D10201, doi:10.1029/2006JD007927, 2007.

Gillette, D. A., Blifford, I. H., and Fryrear, D.: The influence of wind velocity on the size distributions of aerosols generated by the wind erosion of soils, J. Geophys. Res., 79, 4068-4075, 1974.

Ginoux, P., Chin, M., Tegen, I., Prospero, J. M., Holben, B. N., Dubovik, O., and Lin, S.-J.: Sources and distribution of dust aerosols with the GOCART model, J. Geophys. Res., 106, 20255-20273, 2001.

Glaccum, R. A. and Prospero, J. M.: Saharan aerosols over the tropical North Atlantic-Mineralogy, Mar. Geol., 37, 295-321, 1980.

Gomes, L., Bergametti, G., Coudé-Gaussen, G., and Rognon, P.: Submicron desert dusts: A sandblasting process, J. Geophys. Res. Atmos. (1984-2012), 95, 13927-13935, 1990.

Han, Q., Moore, J. K., Zender, C., Measures, C., and Hydes, D.: Constraining oceanic dust depostion using surface ocean dissolved Al, Global Biogeochem. Cy., 22, GB2003, doi:10.1029/2007GB002975, 2008.

Holben, B., Eck, T., Slutsker, I., Tanre, D., Buis, J., Setzer, A., Vermote, E., Reagan, J., Kaufman, Y., and Nakajima, T.: AERONET - A federated instrument network and data archive for aerosol characterization, Remote Sens. Environ., 66, 1-16, 1998.

Holben, B. N., Tanre, D., Smirnov, A., ECK, T. F., Slutsker, I., Abuhassan, N., Newcomb, W. W., Schafer, J. S., Chatenet, B., Lavenu, F., Kaufman, Y. J., Vande Castle, J., O’Neill, N. T., Pietras, C., Pinker, R. T., Voss, K., and Zibordi, G.: An emerging ground-based aerosol climatology:Aerosol optical depth from AERONET, J. Geophys. Res., 106, 12067-12097, 2001.

Hoose, C., Lohmann, U., Erdin, R., and Tegen, I.: The global influence of dust mineralogical composition on heterogeneous ice nucleation in mixed-phase clouds, Environ. Res. Lett., 3, 025003, doi:10.1088/1748-9326/3/2/025003, 2008.

Hurrell, J. W., Holland, M., Gent, P., Ghan, S., Kay, J. E., Kushner, P., Lamarque, J.-F., Large, W., Lawrence, D., and Lindsay, K.: THE COMMUNITY EARTH SYSTEM MODEL, B. Am. Meteor. Soc., 94, 1139-1360, doi:10.1175/BamS-d-12-00121.1, 2013.

Hurrell, J. W., Holland, M. M., Ghan, S., Lamarque, J.-F., Lawrence, D., Lipscomb, W. H., Mahowald, N., Marsh, D., Rasch, P., Bader, D., Collins, W. D., Gent, P. R., Hack, J. J., Kiehl, J., Kushner, P., Large, W. G., Marshall, S., Vavrus, S., and Vertenstein, M.: The Community Earth System Model: A Framework for Collaborative Research, B. Am. Meteor. Soc., 94, 1139-1360, doi:10.1175/BAMS-D-12-00121.1, 2014.

Iacono, M. J., Delamere, J. S., Mlawer, E. J., Shephard, M. W., Clough, S. A., and Collins, W. D.: Radiative forcing by long-lived greenhouse gases: Calculations with the AER radiative transfer models, J. Geophys. Res. Atmos., 113, D13103, doi:10.1029/2008JD009944, 2008.

IPCC: Summary for Policymakers, in: Climate Change 2007: The Physical Science Basis. Contribution of Working Group I to the Fourth Assessment Report of the Intergovernmental Panel on Climate Change, edited by: Solomon, S., Qin, D., Manning, M., Chen, Z., Marquis, M., Averyt, K., Tignor, M., and Miller, H. L., Cambridge University Press, Cambridge, UK and New York, NY, USA, 129-233, 2007.
Jickells, T., An, Z., Andersen, K., Baker, A., Bergametti, G., Brooks, N., Cao, J., Boyd, P., Duce, R., Hunter, K., Kawahata, H., Kubilay, N., laRoche, J., Liss, P., Mahowald, N., Prospero, J., Ridgwell, A., Tegen, I., and Torres, R.: Global iron connections between dust, ocean biogeochemistry and climate, Science, 308, 67-71, 2005.

Joseph, J., Wiscombe, W., and Weinman, J.: The delta-Eddington approximation for radiative flux transfer, J. Atmos. Sci., 33, 2452-2459, 1976.

Journet, E., Desbouefs, K., Caqineau, S., and Colin, J.-L.: Mineralogy as a critical factor of dust iron solubility, Geophys. Res. Lett., 35, L07805, doi:10.1029/2007GL031589, 2008.

Journet, E., Balkanski, Y., and Harrison, S.: A new data set of soil mineralogy for dust-cycle modeling, Atmos. Chem. Phys., 14, 3801-3816, doi:10.5194/acp-14-3801-2014, 2014.

Kalashnikova, O. and Kahn, R. A.: Mineral dust plume evolution over the Atlantic from MISR and MODIS aerosol retrievals, J. Geophys. Res., 113, D24204, doi:10.1029/2008JD010083, 2008.

Kandler, K., Schütz, L., Deutscher, C., Ebert, M., Hofmann, H., Jäckel, S., Jaenicke, R., Knippertz, P., Lieke, K., and Massling, A.: Size distribution, mass concentration, chemical and mineralogical composition and derived optical parameters of the boundary layer aerosol at Tinfou, Morocco, during SAMUM 2006, Tellus B, 61, 32-50, 2009.

Karydis, V., Kumar, P., Barahona, D., Sokolik, I., and Nenes, A.: On the effect of dust particles on global cloud condensation nuclei and cloud droplet number, J. Geophys. Res. Atmos., 116, D23204, doi:10.1029/2011JD016283, 2011.

Kiefert, L., McTainsh, G., and Nickling, W.: Sedimentological characteristics of Saharan and Australian dusts, in: The impact of desert dust across the Mediterranean, Springer, the Netherlands, 183-190, 1996.

Koehler, K. A., Kreidenweis, S. M., DeMott, P. J., Petters, M. D., Prenni, A. J., and Carrico, C. M.: Hygroscopicity and cloud droplet activation of mineral dust aerosol, Geophys. Res. Lett., 36, L08805, doi:10.1029/2009GL037348, 2009.

Kok, J.: A scaling theory for the size distribution of emitted dust aerosols suggests climate models underestimate the size of the global dust cycle, Proceedings of the National Academy of Science USA, 108, 1016-1021, 2011.

Kok, J. F., Parteli, E. J., Michaels, T. I., and Karam, D. B.: The physics of wind-blown sand and dust, Rep. Prog. Phys., 75, 106901, doi:10.1088/0034-4885/75/10/106901, 2012.

Kolmogorov, A. N.: On the logarithmically normal law of distribution of the size of particles under pulverisation, Doklady Akademii Nauk SSSR, 31, 99-101, 1941.

Lamarque, J.-F., Emmons, L., Hess, P., Kinnison, D. E., Tilmes, S., Vitt, F., Heald, C., Holland, E. A., Lauritzen, P., and Neu, J.: CAM-chem: description and evaluation of interactive atmospheric chemistry in the Community Earth System Model, Geoscientific Model Development, 5, 369-411, 2012.

Lancaster, N. and Baas, A.: Influence of vegetation cover on sand transport by wind: field studies at Owens Lake, California, Earth Surf. Proc. Landf., 23, 69-82, 1998.

Levin, Z., Teller, A., Ganor, E., and Yin, Y.: On the interactions of mineral dust, sea-salt particles, and clouds: A measurement and modeling study from the Mediterranean Israeli Dust Experiment campaign, J. Geophys. Res., 110, D20202, doi:10.1029/2005JD005810, 2005. 
Li, F., Vogelman, A., and Ramanathan, V.: Saharan dust aerosol radiative forcing measured from space, J. Climate, 17, 2558-2571, 2004.

Liu, X., Easter, R. C., Ghan, S. J., Zaveri, R., Rasch, P., Shi, X., Lamarque, J.-F., Gettelman, A., Morrison, H., Vitt, F., Conley, A., Park, S., Neale, R., Hannay, C., Ekman, A. M. L., Hess, P., Mahowald, N., Collins, W., Iacono, M. J., Bretherton, C. S., Flanner, M. G., and Mitchell, D.: Toward a minimal representation of aerosols in climate models: description and evaluation in the Community Atmosphere Model CAM5, Geosci. Model Dev., 5, 709-739, doi:10.5194/gmd-5-709-2012, 2012.

Mahowald, N. and Kiehl, L.: Mineral aerosol and cloud interactiocns, Geophys. Res. Lett., 30, 1475, doi:10.1029/2002GL016762, 2003.

Mahowald, N., D. Muhs, Levis, S., Rasch, P., Yoshioka, M., and Zender, C.: Change in atmospheric mineral aerosols in response to climate: last glacial period, pre-industrial, modern and doubled-carbon dioxide climates J. Geophys. Res., 111, D10202, doi:10.1029/2005JD006653, 2006.

Mahowald, N., Kloster, S., Engelstaedter, S., Moore, J. K., Mukhopadhyay, S., McConnell, Albani, S., Doney, S., Bhattacharya, A., Curran, M., Flanner, M., Hoffman, F., Lawrence, D., Lindsay, K., Mayewski, P., Neff, J., Rothenberg, D., Thomas, E., Thornton, P., and Zender, C.: Observed 20th century desert dust variability: impact on climate and biogeochemistry, Atmos. Chem. Phys., 10, 10875-10893, doi:10.5194/acp-10-108752010, 2010.

Martin, J., Gordon, R. M., and Fitzwater, S. E.: The case for iron, Limnology and Oceanography, 36, 1793-1802, 1991.

Miller, R., Tegen, I., and Perlwitz, J.: Surface radiative forcing by soil dust aerosols and the hydrologic cycle, J. Geophys. Res., 109, D04203, doi:10.1029/2003JD004085, 2004.

Miller, R., Cakmur, R., Perlwitz, J., Geogdzhayev, I., Ginoux, P., Kohfeld, K., Koch, D., Prigent, C., Ruedy, R., Schmidt, G., and Tegen, I.: Mineral dust aerosols in the NASA Goddard Institute of Space Sciences ModelE Atmospheric General Circulation Model, J. Geophys. Res., 111, D06208, doi:10.1029/2005JD005796, 2006.

Miller, R. L. and Tegen, I.: Climate Response to Soil Dust Aerosols, J. Climate, 11, 3247-3267, 1998.

Moosmüller, H., Engelbrecht, J. P., Skiba, M., Frey, G., Chakrabarty, R. K., and Arnott, W. P.: Single scattering albedo of fine mineral dust aerosols controlled by iron concentration, J. Geophys. Res. Atmos., 117, D11210, doi:10.1029/2011JD016909, 2012.

Nickovic, S., Vukovic, A., Vujadinovic, M., Djurdjevic, V., and Pejanovic, G.: Technical Note: High-resolution mineralogical database of dust-productive soils for atmospheric dust modeling, Atmos. Chem. Phys, 12, 845-855, doi:10.5194/acp-12-8452012, 2012.

Niklasson, G. A., Granqvist, C., and Hunderi, O.: Effective medium models for the optical properties of inhomogenous materials, Appl. Optics, 20, 26-30, doi:10.1364/AO.20.000026, 1981.

Okin, G.: A new model of wind erosion in the presence of vegetation, J. Geophys. Res.-Earth Surf., 113, F02S10, doi:10.1029/2007JF000758, 2008.

Patadia, F., Yang, E.-S., and Christopher, S.: Does dust change the clear sky top of atmosphere shortwave flux over high sur- face reflectance regions?, Geophys. Res. Lett., 36, L15825, doi:10.1029/2009GL039092, 2009.

Perlwitz, J., Tegen, I., and Miller, R.: Interactive soil dust aerosol model in the GISS GCM 1. Sensitivity of the soil dust cycle to radiative properties of soil dust aerosols, J. Geophys. Res., 106, 18167-18192, 2001.

Rasch, P. J., Feichter, H., Law, K., Mahowald, N., Penner, J., Benkovitz, C., Genthon, C., Giannakopoulos, C., Kasibhatla, P., Koch, D., Levy, H., Maki, T., Prather, M., Roberts, D. L., Roelofs, G.-J., Stevenson, D., Stockwell, Z., Taguchi, S., Chipperfield, M., Baldocchi, D., McMurry, P., Barrie, L., Balkanski, Y., Chatfield, B., Jacob, D., Kritz, M., Lawrence, M., Lee, H. N., Leaitch, R., Lelieveld, J., Noone, K. J., Seinfeld, J., Stenchikov, G., Schwarz, S., Walcek, C., and Williamson, D.: An Assessment of Scavenging and Deposition Processes in Global Models: Results from the WCRP Cambridge Workshop of 1995, Tellus, 52B, 1025-1056, 2000.

Reid, E., Reid, J., Meier, M., Dunlap, M., Cliff, S., Broumas, A., Perry, K., and Maring, H.: Characterization of African dust transported to Puerto Rico by individual particle and size segregated bulk analysis, J. Geophys. Res.-Atmos., 108, 8591, doi:10.1029/2002JD002935, 2003.

Sabre, M., Lopez, M., Alfaro, S., Rajot, J., and Gomes, L.: Characterization of the fine dust particle production process by wind erosion for two types of bare soil surfaces, Proceedings of Wind Erosion: An International Symposium/Workshop, 3-5 June 1997, Manhattan, Kansas, USA, 1997.

Schulz, M., Balkanski, Y. J., Guelle, W., and Dulac, F.: Role of aerosol size distribution and source loaction in a threedimensional simulation of a Saharan dust episode tested against satellitle-derived optical thickness, J. Geophys. Res., 103, 10579-10592, 1998.

Seinfeld, J. and Pandis, S.: Atmospheric Chemistry Physics, John Wiley and Sons, Inc, New York, 1326 pp., 1998.

Shao, Y., Raupach, M., and Findlater, P.: Effect of saltation bombardment on the entrainment of dust by wind, J. Geophys. Res. Atmos. (1984-2012), 98, 12719-12726, 1993.

Shen, Z., Li, X., Cao, J., Caquineau, S., Wang, Y., and Zhang, X.: Characteristics of clay minerals in Asian dust and their environmental significance, China Particuol., 3, 260-264, 2005.

Shi, Z., Shao, L., Jones, T., and Lu, S.: Microscopy and mineralogy of airborne particles collected during severe dust storm episodes in Beijing, China, J. Geophys. Res. Atmos., 110, D01303, doi:10.1029/2004JD005073, 2005.

Siegel, D. A. and Deuser, W. G.: Trajectories of sinking particles in the Sargasso Sea: modeling of statistical funnels above deepocean sediment traps, Deep-Sea Res., 44, 1519-1541, 1997.

Sokolik, I. N. and Toon, O. B.: Incorporation of mineralogical composition into models of the radiative properties of mineral aerosol form UV to IR wavelengths, J. Geophys. Res., 104, 9423-9444, 1999.

Suarez, M. J., Rienecker, M., Todling, R., Bacmeister, J., Takacs, L., Liu, H., Gu, W., Sienkiewicz, M., Koster, R., and Gelaro, R.: The GEOS-5 Data Assimilation System-Documentation of Versions 5.0. 1, 5.1. 0, and 5.2. 0, http://ntrs.nasa.gov/archive/nasa/ casi.ntrs.nasa.gov/20120011955.pdf (last access: 30 June 2014), 2008.

Swap, R., Garstang, M., Greco, S., Talbot, R., and Kallberg, P.: Saharan dust in the Amazon Basin, Tellus, 44B, 133-149, 1992. 
Wang, H., Easter, R., Rasch, P., Wang, M., Liu, X., Ghan, S., Qian, Y., Yoon, J.-H., Ma, P.-L., and Velu, V.: Sensitivity of remote aerosol distributions to representation of cloud-aerosol interactions in a global climate model, Geosci. Model Dev., 6, 765-782, doi:10.5194/gmd-6-765-2013, 2013.

Wiscombe, W. J.: Improved Mie scattering algorithms, Appl. Opt., 19, 1505-1509, 1980.

Woodward, S.: Modeling the atmopsheric life cycle and radiative impact of mineral dust in the Hadley Centre climate model, JGR, 106, 18155-118166, 2001.

Yin, Y., Wurzler, S., Levin, Z., and Reisin, T. G.: Interactions of mineral dust particles and clouds: Effects on precipitation and cloud optical properties, J. Geophys. Res. Atmos., 107, AAC 191-AAC 19-14, doi:10.1029/2001JD001544, 2002.

Yoshioka, M., Mahowald, N., Conley, A., Collins, W., Fillmore, D., and Coleman, D.: Impact of desert dust radiative forcing on Sahel precipitation: relative importance of dust compared to sea surface temperature variations, vegetation changes and greenhouse gas warming, J. Climate, 20, 1445-1467, 2007.
Zender, C., Bian, H., and Newman, D.: Mineral Dust Entrainment and Deposition (DEAD) model: Description and 1990s dust climatology, J. Geophys. Res., 108, 4416, doi:10.1029/2002JD002775, 2003.

Zhang, J. and Christopher, S.: Long wave radiative forcing of Saharan dust aerosols estimated from MODIS, MISR and CERES observations on TERRA, Geophys. Res. Lett., 30, 2188, doi:10.1029/2003GL018479, 2003.

Zhang, Y., Mahowald, N., Scanza, R., Journet, E., Desboeufs, K., Albani, S., Kok, J., Zhuang, G., Chen, Y., Cohen, D. D., Paytan, A., Patey, M. D., Achterberg, E. P., Engelbrecht, J. P., and Fomba, K. W.: Modeling the global emission, transport and deposition of trace elements associated with mineral dust, Biogeosciences Discuss., 11, 17491-17541, doi:10.5194/bgd-11-17491-2014, 2014. 